\title{
When organisations and ecosystems interact: toward a law of requisite fractality in firms
}

\author{
Bill McKelvey* \\ Euromed Management School, \\ Rue Antoine Bourdelle, \\ Domaine de Luminy BP 921 , \\ 13288 Marseille Cedex 9, France \\ E-mail: mckelvey@anderson.ucla.edu \\ *Corresponding author
}

\section{Benyamin B. Lichtenstein}

Management/Marketing Department, University of Massachusetts, 100 Morrissey Blvd., M5/214, Boston, MA 02125, USA

E-mail: benyamin.bml@gmail.com

\section{Pierpaolo Andriani}

Euromed Management School, Rue Antoine Bourdelle, Domaine de Luminy BP 921, 13288 Marseille Cedex 9, France

E-mail: pier2paolo@gmail.com

\begin{abstract}
Complexity science has evolved greatly in the past 30 years, starting from its European roots in Prigogine's dissipative structures model of phase transitions, continuing through the Santa Fe School's focus on self-organised adaptation as explained through computational simulations, and now to it's most recent focus on power laws and their basis in scale-free causes. After briefly reviewing these three approaches to complex systems, we attempt to integrate them into a broad-based model of organisational design and performance. Our model develops the law of 'requisite fractality' - an updated version of Ashby's original law for organisations in dynamic environments. Implications for organisations and managers are discussed.
\end{abstract}

Keywords: complexity science; dissipative structures; self-organisation; power laws; scale-free causes; organisation design; requisite fractality; Ashby's law; dynamic environments; implications.

Reference to this paper should be made as follows: McKelvey, B., Lichtenstein, B.B. and Andriani, P. (2012) 'When organisations and ecosystems interact: toward a law of requisite fractality in firms', Int. J. Complexity in Leadership and Management, Vol. 2, Nos. 1/2, pp.104-136. 
Biographical notes: Bill McKelvey is an Emeritus Research Professor of Strategic Organising, Complexity Science, and Econophysics at the UCLA Anderson School of Management. His book, Organizational Systematics (1982) remains the definitive treatment of organisational taxonomy and evolution. He chaired the building committee that produced the $\$ 110,000,000$ Anderson Complex. He co-edited Variations in Organization Science (with J. Baum, 1999), a special issue of Emergence (with S. Maguire, 1999), and a special issue of Int. J. Complexity in Leadership \& Management (2013). He is Co-Editor of SAGE Handbook of Complexity and Management (2011). He is the Editor of Routledge Major Work: Complexity: Critical Concepts (2012; five-volumes, $2000 \mathrm{pp}$.). He has $70+$ papers on organisational complexity since 1997.

Benyamin B. Lichtenstein is an Associate Professor of Entrepreneurship and Management at the University of Massachusetts, Boston. His research explores emergence - the coming-into-being of organisations, projects, and social entities; he is currently writing a book on the topic for Oxford University Press. His three other books and $40+$ papers have used the complexity sciences to explore new venture creation, organisational change and transformation, relationality, and sustainability. He has published in journals such as Organization Science, Journal of Business Venturing, Entrepreneurship Theory and Practice, and Human Relations.

Pierpaolo Andriani is an Associate Professor of Complexity and Innovation Management at Euromed Management in Marseille, France. He received his $\mathrm{PhD}$ from Durham University, UK. His research interests are focused on the impact of complexity theory on innovation, organisational theory and entrepreneurship. His research has been published in journals such as Organization Science, Journal of International Business Studies and Long Range Planning.

'I think the next century will be the century of complexity', Stephen Hawking ${ }^{1}$

\section{Introduction}

Complexity science has been heralded as new paradigm in management - a powerful set of methods for explaining non-linear, emergent behaviour in organisations (Stacey, 1992; Brown and Eisenhardt, 1997; McKelvey, 1997; Anderson et al., 1999; Maguire et al., 2006). Many specific theoretical notions of complexity science have already been tested using computational experiments, including key aspects of learning (Carley and Svoboda, 1996), organisation design (Levinthal and Warglien, 1999), network structuring (Carley, 1999; Lenox et al., 2006), organisational evolution (Allen, 1975, 1988, 1994; Levinthal, 1997; Morel and Ramanujam, 1999; Levinthal and Posen, 2007), strategic human resource management (Colbert, 2004) and strategic adaptation (Gavetti and Levinthal, 2000; Rivkin, 2001; Siggelkow and Levinthal, 2005; Siggelkow and Rivkin, 2006), to name just a few.

At least three problems block further progress toward applying complexity in management. First, even though the expressed focus of complexity science is the emergence of order, management applications of complexity rarely define what emergence is - there is no accepted definition for emergence in the field. More importantly, most non-computational applications do not reveal the underlying processes 
and dynamics of self-organisation, which is said to be the driver of emergence (Holland, 1995).

Second, many writers convert core concepts from complexity science into simple metaphors that appear to offer managers 'hard' science legitimation for loose thinking about non-linearities, and for their use of traditional employee empowerment theory, which in many of these 'O.D.' approaches is seen as an application of the 'emergence principle' (McKelvey, 1999). As such, many of the fundamental principles from complexity science are inappropriately applied to organisations, and as a result, the community has not learned as much from complexity science as it should (Maguire and McKelvey, 1999).

Third, this problem is compounded by a significant split between two schools of thought within the complexity field itself (McKelvey, 2004). The European School, originating from Prigogine's dissipative structures theory (Prigogine, 1955; Prigogine and Stengers, 1984), explores the dynamics that initiate and sustain order creation in far-fromequilibrium environments. In contrast, the American School, represented primarily by the coevolution-framed work coming out of the Santa Fe Institute (Anderson et al., 1988; Arthur, 1988; Holland, 1988; Kauffman, 1993; Gell-Mann, 1994; Cowan et al., 1994), explores the form and inter-system processes associated with emergent order: agent heterogeneity, agent interactions, co-evolution, and the 'edge of chaos'. Not only have these two Schools generated seemingly contradictory approaches for explaining emergence, their epistemic and ontological turf-war has slowed the drive toward a single overarching complexity framework. ${ }^{2}$

This turf-war is particularly unfortunate due to the critical need to develop managerial practices that, unlike industrial age models, are relevant to 21 st century issues, including the emergence of intangible assets, the rise of a digitised knowledge-based economy, globalisation, the sustainability imperative, and the increased importance of emerging organisations and emerging markets (Sanders and McCabe, 2003; Maguire et al., 2004). These dynamics are driven by new order creation, rather than by traditional notions of control, efficiency, economies of scale, equilibrium, and so on (Halal and Taylor, 1999). Complexity science is the study of order creation - the only science dedicated to explaining how new order emerges through self-organisation in physical, biological, and social systems (Kauffman, 1993; Mainzer, 1994/2007; Chaisson, 2001, McKelvey, 2004). Given that complexity is unique in this respect, providing a complexity-sciencebased theory of emergent order creation that applies to organisations is foundationally important.

One place where the international community of complexity researchers has come together is on discoveries pertaining to Pareto distributions, power laws (PLs), and scale-free theory - best signified by the references in Andriani and McKelvey (2007, 2009) and McKelvey and Salmador Sanchez (2011). Our goal here is to build on earlier research (McKelvey and Lichtenstein, 2007; Lichtenstein and McKelvey, 2012) in which we explain the 'bottom-up emergence' of organisations in terms of four stages or levels: emergent networks, emergent groups, emergent hierarchy, and emergent coordination complexity. Each of these levels is well expressed in existing agent-based computational models of emergence in organisations. In this article we expand this idea by considering the fractal structures which emerge across these and further levels, as organisations adapt to their dynamic environments. We also build on McKelvey and Boisot's (2009) updating of Ashby's (1956) Law of Requisite Variety to develop and our proposed Law of Requisite Fractality and apply it to organisations. 
We start by drawing on the key insights of the European School to explain the driver that initiates self-organising dynamics in economic and organisational contexts. Next, we combine the American School's early insights into the form of self-organised structures and especially Bak's (1996) work on 'self-organised criticality' - with the more recent international research on PLs, fractals, and scale-free theory. Finally we cite 19 biological studies of interacting fractal eco-structures and draw as well on various scale-free theories from Andriani and McKelvey (2009) to substantiate our proposed Law of Requisite Fractality.

\section{Emergence: what are we looking for?}

An ever-proliferating range of meanings and operationalisations can be found for emergent order in management. For example, Winter (1984) looks at the emergence of economic order in a competitive yet growing industry, Axelrod and Bennett (1993) define order in terms of emergent outcomes of co-evolutionary games, Cheng and Van de Ven (1996) define order through the emergence of 'strange attractors' in two innovation projects; Brown and Eisenhardt (1997) define order as the emergence of dynamic yet balanced structuring; Levinthal (1991) defines order as the levels of strategic adaptiveness that emerge in competitive conditions; and MacIntosh and MacLean (1999) define order as the emergence of structure in far-from-equilibrium strategic situations. Ironically, only by putting some order into the definition of order can complexity science make a coherent contribution to organisation studies (Cohen, 1999).

For over 100 years the question of what is emergence has intrigued and dogged scholars from many disciplines, including philosophers (Lewes, 1877; Pepper, 1926; Stephen, 1992), evolutionists (Darwin, 1859; Baldwin, 1896, 1902; Morgan, 1923; Fisher, 1930; Eldredge and Gould, 1972; Kauffman, 1993; Salthe, 1993), complexity scientists (Prigogine, 1955; Allen, 1975; Holland, 1988; Nicolis and Prigogine, 1989; Crutchfield, 1994; Mainzer, 1994); and a wide range of management scholars (Selznick, 1943; Homans, 1950; Burns and Stalker, 1961; Weick, 1977; Goldstein, 1986; Stacey, 1992; McKelvey, 1997; Malnight, 2001; Chiles et al., 2004).

An initial approach, taken by the evolutionary emergentists, was to develop a non-deductive explanation of the qualitative novelty expressed by successive levels of reality (Blitz, 1992). In Newman's (1996, p.247) words, 'For an emergent evolutionist, a property of a system is emergent if its existence is novel at the level of evolutionary or physical complexity in which the system is found'. This leads to a modern definition of emergence as a systemic process of order creation through which properties and or structures come into being that are unexpected and unpredictable, given the known attributes of component agents ${ }^{3}$ and environmental forces. Although this definition is not without merit, in some measure it has not progressed much further than the definition offered in 1938 by sociologist Herbert Mead:

\footnotetext{
"When things get together, there then arises something that was not there before, and that character is something that cannot be stated in terms of the elements, which go to make up the combination. It remains to be seen in what sense we can now characterize that which has so emerged." [Mihata, (1997), p.30].
}

The goal of complexity science is to characterise that which has so emerged. A critical problem is that emergence is being explained in two very different ways by two 
contrasting schools of complexity. Like the blind people looking at the elephant, we believe that insights from each view are crucial but incomplete. Thus, we briefly introduce these different views, and explore why this difference makes a difference in complexity.

\subsection{The European view: emergence as energy-induced phase transitions}

The European perspective draws from Prigogine's (1955) and Nicolis and Prigogine (1989) research into phase transitions at what is called the '1st critical value', $R_{C 1}-$ the 'edge of order'. When imposed energy levels tip across $R_{C 1}$, 'dissipative structures' form; these are emergent 'self-organised' structures that speed up the dissipation of imposed energy differentials, by creating new intra-system order. Essentially, environmentally imposed energy differentials generate an 'adaptive tension' in the system, giving it an inherent drive to be dissipated (Wicken, 1986; McKelvey, 2008).

This approach has been used to explain a broad range of organisational, sociological, and economic phenomena (e.g., Weick, 1977; Schieve and Allen, 1982; Ulrich and Probst, 1984; Adams, 1988; Smith and Gemmill, 1991; De Vany, 2004; Zohar and Borkman, 1997; Dosi and Fagiolo, 1998; Lesourne and Orlean, 1998; Saviotti and Mani, 1998; Lichtenstein et al., 2007). For example, a technical or process innovation (Schumpeter, 1934; Tushman and Anderson, 1986) can set up disequilibrium between the entrepreneur and the current market; these innovations drive the self-organised emergence of new firms and new industries (Binks and Vale, 1990; Foster, 2000). Slevin and Covin (1997, p.56) describe this process by suggesting that 'successful entrepreneurial firms act as energy conversion systems'. In a broader managerial context Anderson (1999, p.222) suggests that adaptive tension may be generated by organisational leaders:
"Those with influence and/or authority turn the heat up...on an organization by recruiting new sources of energy (e.g., members, suppliers, partners, and customers), by motivating stakeholders, by shaking up the organization, and by providing new sets of challenges that cannot be mastered by hewing to existing procedures."

By this theory, organisations and their internal structures emerge by importing locally accessible bundles of order, e.g., opportunities and resources (Schrödinger, 1944; Dyke, 1988; Frederick, 1998). In management terms, an entrepreneur imagines and identifies a 'bundle' of potential resources that $\mathrm{s} / \mathrm{he}$ can transform into value for customers by organising a new venture (Gartner, 1985). This projection of possibility generates an 'opportunity tension' inside the entrepreneur (Lichtenstein, 2010), who

a gains an insight about a possible market or the capacity to do something 'better, cheaper, faster'

b is motivated by a 'creative tension' (Fritz, 1989) to make his/her idea a reality (Adler and Obstfeld, 2006).

In literal terms this process is opportunity intention - the identification/enactment of a business opportunity with the internal motivation/passion to do what it takes to make it happen (Gartner et al., 1992).

Assuming a substantive increase in resource flow driven by opportunity tension by an entrepreneurial leader, the theory then makes a very strong hypothesis: at a minimum 
threshold of bifurcation, new order will emerge as rapidly as possible in the system, i.e., as soon as enough resources are available (Swenson 1989, 1992, 1997). That is, in the absence of other constraints, new order will self-organise instantaneously (Getling and Brausch, 2003) in order to dissipate new energy potentials at the maximal rate (Swenson, 1992, 1997; Lichtenstein, 2000; McKelvey, 2004). Since the most efficient way to dissipate these tensions is through endogenous order production (i.e., order creation), that's what will happen. Essentially, the biological and social world is in the 'order production' business.

Our approach runs deeper yet parallel to original versions of general systems theory (von Bertalanffy, 1956, 1968; Bateson, 1972; Miller, 1978), by describing organisations as a series of nested systems, each level increasingly complex as it is generated through the interactions of its lower-level components (Ashmos and Huber, 1987; Chaisson, 2001). Assuming an initial condition of multiple, heterogeneous agents in an environment that is already imposing some form of adaptive tension, we would expect to see emergence appear as a progression of increasingly complex stages of organising (Miller, 1978; Adams, 1988; Salthe, 1985), which of course is what we see in the social world (Boulding, 1988).

The European view thus shows how adaptive tension drives the emergence of intra-system order within organisations. Europeans have long explored this ordering process, seeking to explain how agents-that-emerge create clear boundaries and identities amidst interdependent interactions. For example, Maturana and Varela (1980) develop their theory of autopoiesis to explain how biological entities understand the world around them in the presence of this constant order-creation process that defines who and what they are. Autopoiesis and autogenesis also provide unique explanations for organisational identity (Drazin and Sandelands, 1992) and growth (Csanyi and Kampis, 1985), as well as shared cognition in social settings (Maturana and Varela, 1987).

We now ask a broader question: Is there a pattern to these stages of emergence across multiple organisational levels? This question is a core focus of the American School of complexity.

\subsection{The Santa Fe view: emergence from continuously adapting heterogeneous agents}

The American School consists largely of people associated with the Santa Fe Institute (Pines, 1988; Anderson et al., 1988; Cowan et al., 1994; Arthur et al., 1997). In contrast to the Europeans' focus on dramatic phase transitions at the 1 st critical value, $R_{C 1}$, that give rise to new levels of order-dissipative-structures within a system, US complexity scientists focus on the upper bound of criticality, $R_{C_{2}}$ - the 2 nd critical value, originally known as the 'edge of chaos' (Lewin, 1992/1999; Kauffman, 1993). What happens at $R_{C 1}$ is better understood; what happens at $R_{C 2}$ is more obscure. As such, the US complexity literature focuses on the intra-system processes of emergent complexity, especially the ways that coevolution and seemingly insignificant triggering effects can generate self-organising structures that have a consistent form or pattern.

One of the key insights from the American School is the critical role that interdependence plays in the emergence of order. Kauffman's work on $N K$ landscapes shows how the order that emerges is dependent not on the number, $N$, of agents but on the degree of interdependence, $K$, of the agents in the system. Management scholars have gained various insights from this work. For example, looking at the explorative process 
of invention, Fleming and Sorenson (2001, p.1025) show that the value and quality of inventions are dependent on the degree of interaction between their components, not on the number of components that an innovator is hoping to combine.

Interdependence among agents creates a kind of 'basin of attraction' for emergent order in 'edge cities' (Krugman, 1996), and it is at the core of Marion's (1999) useful framework of 'complex attractors' in organisations. In a different way, Holland's (1995, 1998) innovations pertaining to genetic algorithms are based on the idea that agents become increasingly interdependent as they interact and exchange knowledge and resources with each other. Likewise, studies of interdependent interactions across industries show how the evolution of organisations and institutions is a kind of 'self-organising' process (Malerba et al., 1999).

An advanced stream of this research shows how computational agents with heterogeneous levels of knowledge and other traits, will self-organise multiple nested-levels of order as they follow a small number of 'motivating' rules. For example, Carley's (1990) 'ORGAHEAD' model consists of knowledge workers in emergent groups that create their own 'rules' of interaction derived from strategies that emerge from an executive team - which itself generates a culture that influences the workers, groups and organisation as a whole. Other multi-level emergent models have been designed, including early ones by Epstein and Axtell (1996) and Paul et al. (1996).

\subsection{The econophysics view: scale-free theory}

An important implication of the US approach is the idea that emergent organising, when extended to multiple levels within a system, often takes on certain patterns that can be explained using a single rule or function. Researchers in this tradition use these simple functions - so-called 'scale-free' causes that are identified by PLs - to make scalable connections across multiple levels of dynamic systems. Making these connections is tantamount to developing theories of emergence that are scale-free - i.e., that utilise the same simple repeating explanatory functions across multiple levels of organisational behaviour. For example, Brock (2000, pp.29-30) expresses the importance of scaling laws to a theory of emergence as follows:

\footnotetext{
"The study of complexity considers whether these patterns [of emergence] have a property of universality about them.... [Complexity] tries to understand the forces that underlie the patterns or scaling laws that develop [as newly ordered systems emerge]."
}

Bak (1996) provided one of the first extended treatments of this insight in his discovery of 'self-organized criticality' - a process represented by a simple PL - in which small initial events can lead to complexity cascades of avalanche proportions. Arthur (1988, 1990) also focuses on positive feedbacks stemming from initially small instigation events; as do Casti (1994) and Brock (2000). Europeans have also been at the vanguard of this project, starting with Mandelbrot $(1975,1982)$. His work on 'fractal geometry' introduced the notion of 'scalability' - in certain contexts like coastlines, clouds and cauliflowers, no matter what the scale of measurement, the phenomena appear the same.

For example, cut off a 'floret' of a cauliflower, then cut-off a smaller branch, then an even smaller one. Each subcomponent (i.e., fractal) is smaller than the former yet each has the same shape and structure. They exhibit a ' $P L$ effect' because they shrink by a fixed ratio. Cauliflowers - and all examples of PLs - call for 'scale-free' explanations 
because the same 'theory' or causal dynamic applies to each of the different levels in turn.

PL effects are Pareto distributed, as opposed 'normally' (i.e., Gaussian) distributed. Pareto distributions are also known by the ' $80-20$ ' rule: $80 \%$ of the outcome is generated by only $20 \%$ of the sample, whereas the other $80 \%$ have virtually no impact at all. For example, $80 \%$ of all phone calls are made by only $20 \%$ of all phone callers, $80 \%$ of sales are made by the top $20 \%$ of salespeople. Statistically, Pareto distributions have very 'long tails', nearly infinite variance, unstable means, and unstable confidence intervals. Oppositely, Gaussian distributions have vanishing tails - allowing for limited variance and stable means - and confidence intervals that are clearly defined and narrow. The overall result is statistical significance that is very easy to demonstrate but has virtually no significance to managers - a point that reflects scholars' overall belief in general linear reality (Abbott, 1988) to the exclusion (up to now) of an organisation science of non-linearity and disequilibrium (Meyer et al., 2005; Andriani and McKelvey, 2007, 2009, 2011).

PLs are ubiquitous in nature and society (Zipf, 1949; Casti, 1994; Newman, 2005; Andriani and McKelvey, 2007, 2009). For example, cities follow a PL when ranked by population (Auerbach, 1913; Zipf, 1949; McKelvey, forthcoming). The structure of the internet follows a PL (Albert et al., 2000), as does the internal structure of growing firms (Stanley et al., 1996). Axtell (2001) shows that US firms are PL distributed. Glaser (2009) shows that firms' market capitalisation is PL distributed.

Clearly, fractals - and the scale-free regularities they represent - are not idle mathematical curiosities. PLs have been found at every level of reality (across 32 orders of magnitude): from the smallest atomic structures measured in nano-metres, i.e., 0.00000000001 metre, to the largest galactic structures we know of measured in mega-parsecs: 1,000,000,000,000,000,000,000 metres (Baryshev and Teerikorpi, 2002). In biology, West and Brown (2004) use fractal geometry of distribution of resources to demonstrate a PL relationship between the mass and metabolism of virtually every organism and its components across 27 orders of magnitude (of mass). Andriani and McKelvey $(2007,2009)$ list $\sim 140$ kinds of PLs ranging from atoms to galaxies, DNA to species, and networks to wars. Table 1 presents a partial list from their work, focusing on social and organisational scale-free phenomena. McKelvey and Salmador Sanchez (2011) list an additional $80+$ in financial economics.

In a formal sense, a scale-free theory of management is based on the premise that a single process - a specific set of sequences, patterns, and behaviours (Lichtenstein and Plowman, 2009) - drives order creation at every level of specific phenomena (Kaye, 1993; Casti, 1994; West et al., 1997). This new research program seeks to identify which organisational phenomena are scale-free, and find the simplest explanation for all the levels involved (Bak and Chen, 1991; Stanley et al., 1996).

As Table 1 shows, there is good reason to believe that PL effects occur frequently in organisations and have far greater consequence than current users of statistics presume (Andriani and McKelvey, 2007). To the extent this is true, researchers ignoring PL effects risk drawing false conclusions in their articles and promulgating useless advice to managers. This because what is important to most managers are the extremes they face, not the averages. 
Table 1a Power laws in the social world

\begin{tabular}{|c|c|c|c|}
\hline Language word usage & $\begin{array}{l}\text { Distribution of } \\
\text { wealth }\end{array}$ & Casualties in war & $\begin{array}{l}\text { Global terrorism } \\
\text { events }\end{array}$ \\
\hline Social networks & $\begin{array}{l}\text { Publications and } \\
\text { citations }\end{array}$ & Deaths of languages & Changing language \\
\hline $\begin{array}{l}\text { Structure of the } \\
\text { WWW }\end{array}$ & Co-authorships & Delinquency rates & Sexual networks \\
\hline Size of villages & Actor networks & \multicolumn{2}{|c|}{$\begin{array}{l}\text { Aggressive behaviour among boys during } \\
\text { recess }\end{array}$} \\
\hline \multicolumn{2}{|c|}{ News website visitation decay patterns } & \multicolumn{2}{|c|}{$\begin{array}{l}\text { Macroeconomics effects of zero rational } \\
\text { agents }\end{array}$} \\
\hline \multicolumn{2}{|c|}{ Structure of internet hardware } & \multicolumn{2}{|c|}{ Number of hits received from website per day } \\
\hline
\end{tabular}

Table 1b Power laws in the organisational world

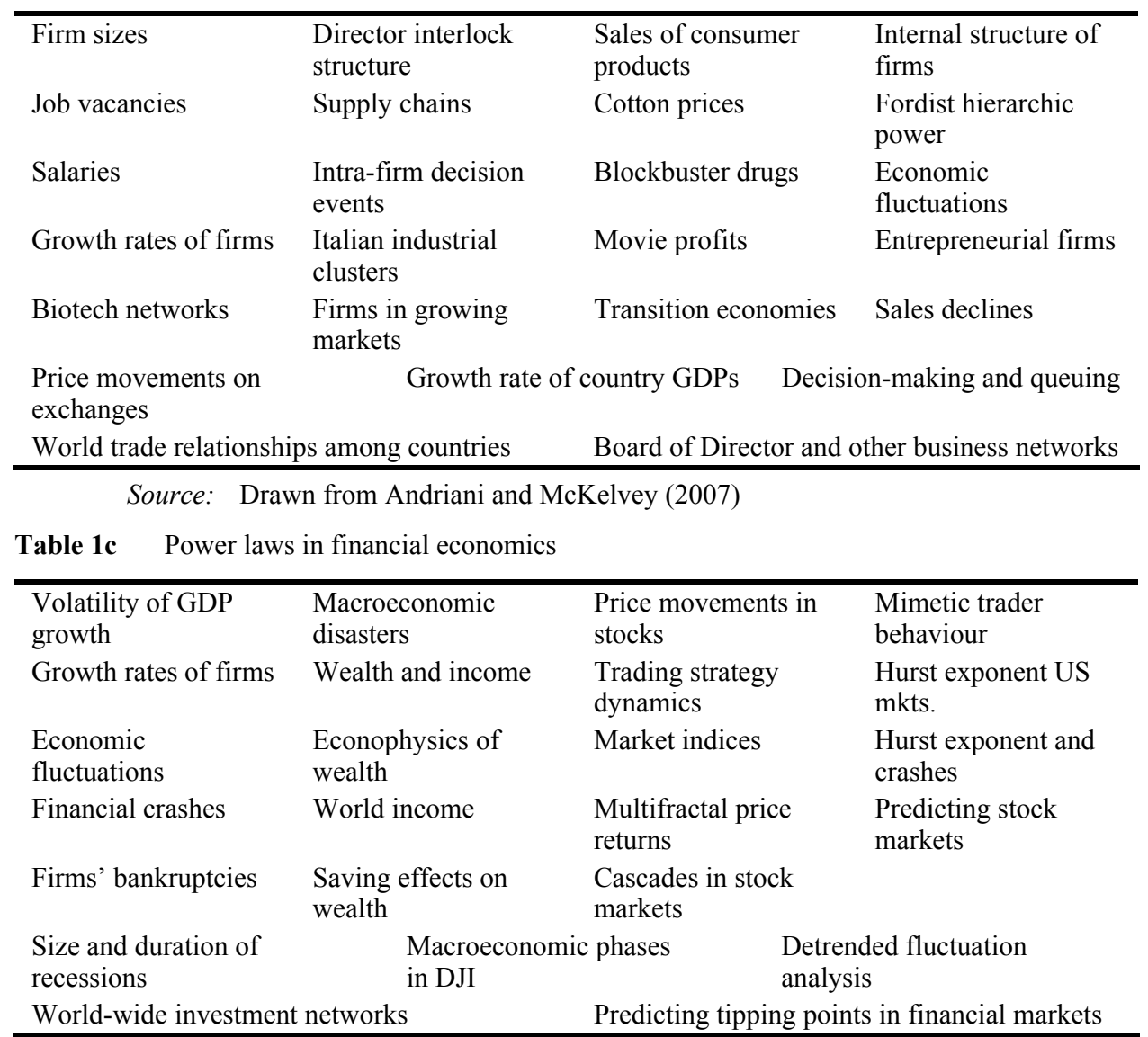

Source: Drawn from McKelvey and Salmador Sanchez (2011)

To be fair, not all management phenomena display PL effects. In natural science, as a comparison, data points are frequently independent. Further, PLs may result from causes other than interdependence-caused fractals (Andriani and McKelvey, 2009). Interdependence, nevertheless, is a common cause of PL effects and Pareto distributions. As the world becomes increasingly interconnected because of globalisation and digital 
technology (resulting in the internet, email, mobile phones, etc.) the probability of Pareto distributions and fractal structures is significantly increased (Boisot and McKelvey, 2010, 2012; Battison et al., 2012).

\subsection{A synthetic approach to emergence}

In summary, the European School of complexity explores the dynamic processes that give rise to emergent behaviour in far-from-equilibrium systems. Guided by Prigogine's theory of dissipative structures, this approach explains the order creation process within complex adaptive systems, a process that is initiated by environmentally imposed adaptive tensions on the system. In effect, this theory explains how imposing forces (i.e., adaptive tensions) drive the emergence of order creation across levels, including the creation of units, components, and structures.

In contrast, the American School of complexity explores the region within which self-organising behaviour takes place, and the form that such behaviour takes when examined across multiple levels of organising. Guided by research at the region of emergent complexity - at the so-called 'edge of chaos' - and self-similarity theory, it studies the pattern of order emerging across multiple levels of complex adaptive systems, a pattern that is initiated through internal system characteristics. In effect, this approach explains how intra-system characteristics and forces drive the emergence of order across systems.

The third view, from econophysics, suggests PLs describe the outcomes of unfettered self-organising behaviour in organisations and industries. These dynamics result in fractal structures. They are explained by scale-free theories.

Drawn together, these three approaches provide a more complete and useful explanation for emergent order, particularly in its forms within and across organisations. With this new synthesis as context, we now review what complexity studies tell us about emergence in organisations.

\section{Toward a fractal theory of organisation}

In this section, we apply lessons from econophysics to organisations by updating Ashby's (1956) classic Law of Requisite Variety. We draw on a few of the 15 scale-free theories identified by Andriani and McKelvey (2009) to make our argument that a principal means by which organisations adapt to their external competitive environment is by understanding how various fractal dynamics associated with the emerging stages can both help and disrupt efficacious adaptation.

\subsection{From outside in: building from Ashby's law}

In his classic work, An Introduction to Cybernetics, Ashby (1956, pp.131-134) says:

"When a constraint exists advantage can usually be taken of it... Every law of nature is a constraint... Science looks for laws... Constraints are exceedingly common in the world around us... A world without constraints would be totally chaotic... That something is predictable implies that there exists a constraint... Learning is worth while only when the environment shows constraint." 
He also notes that order (organisation) exists between two entities, $A$ and $B$, only if the link is 'conditioned' by a third entity, $C$ [Ashby, (1962), p.255]. If $C$ symbolises the 'environment', which is external to the relation between $A$ and $B$, environmental constraints are what cause order (Ashby, 1956). This, then, gives rise to his famous Law of Requisite Variety: 'Only variety can destroy variety' (p.207). It holds that for a biological or social entity to be efficaciously adaptive, the variety of its internal order must match the variety of the environmental constraints. Since 'variety' equates to 'degrees of freedom' and the latter phrase is the signature definition of complexity (Gell-Mann, 1994), we can safely update Ashby's law as follows:

- only internal variety can destroy external variety

- only internal degrees of freedom can destroy external degrees of freedom

- only internal complexity can destroy external complexity

- only internal fractality can destroy external fractality.

In describing the Santa Fe Institute's vision, Brock (2000, p.29) says,

"The study of complexity...is the study of how a very complicated set of equations can generate some very simple patterns for certain parameter values. Complexity considers whether these patterns have a property of universality about them. Here we will call these patterns scaling laws."

In this view, as soon as phenomena are described as 'complex' then they also are seen as fractal, which justifies our last 'update' above, that only requisite internal fractality can destroy external fractality.

Ashby, thus identifies a key law of systemic complexity, namely that in order to remain viable, a system needs to generate the same degree of internal variety as the external variety it faces in the environment. Formally, ' $R$ ' $S$ capacity as a regulator cannot exceed $R$ 's capacity as a channel of communication' [Ashby, (1956) p.211]. Essentially, external complexity - including 'disturbances' or uncertainty - can only be managed or 'destroyed' by matching it with a similar degree of internal complexity.

The first lesson from Ashby is that for strategists to find emerging patterns in what appear to be chaotic environments, they need to uncover the contextual constraints. The second lesson is that degrees of freedom (complexity) within a firm need to match the degrees of freedom among environmental constraints. A third, related lesson comes from Allen (2001). Since it is impossible to know in advance which of a firm's degrees of freedom will actually be relevant to a particular environment, Allen proposes his 'Law of Excess Variety'. A firm can't simply create internal variety to match the environment. It has to create excess variety. It follows that a pattern-finding social network within a firm has to be more complex than the complexity of its competitive environment.

The creation of internal variety has been described at multiple levels of management theory. The very study of cognitive schema is based on the simplified concept that in order to operate effectively in organisational or social settings our internal constructions of the world (mental models) must be representative of the complexity we experience (Boulding, 1956a). When faced with phenomena that fall outside our schema we may expand our schema (increase our requisite variety) to account for these unaccountable experiences (Boulding, 1956b) or restrict our perception of reality (mitigate external variety) to rationalise or simply deny the conflicting information (Staw et al., 1981). Gell-Mann (2002) argues that one has to work toward 'effective complexity' basis of 
schema formation. McKelvey and Boisot (2009) discuss ways of both reducing environmental complexity from possible to probable variety as well as, then, expanding internal complexity to cope with probable external complexity.

In entrepreneurial leadership settings, management scholars suggest that facing the challenges of more complex organisations requires the adoption of a more complex style of thinking, by developing for example a more 'complicated understanding' of organisational phenomena (Bartunek et al., 1983). This view is supported by Weick and Robert's (1993) recognition that dealing with the extremely complex dynamics of landing planes on an aircraft carrier requires a mutually constructive and complicating process of 'heedful interrelating'. This approach is reflected in research that shows how complex organisational problems may sometimes be solved by greatly expanding the contextual information surrounding the problem (i.e., increasing requisite variety), through situated learning (Lave and Wenger, 1991; Orlikowski, 1996) or through communities of practice (Brown and Duguid, 1991) which benefit from the accumulated knowledge of many agents.

\subsection{Requisite fractal structure from emergent stage dynamics}

A PL explanation of emergence stages. Dissipative structures theory tells us when new order via phase transition will appear - such as the four 'levels' we find in the computational and narrative studies. However, this theory says virtually nothing about the form of these changes. PL theory, in contrast, argues that each emergent level will occur much less often and is dependent on the appearance of a prior stage. Specifically, each stage will emerge an order of magnitude less frequently than the prior (and thus more likely) emergent stage. The key point is that each step in this hierarchy of order has a decreasing probability of occurrence; the probability of reaching early stages of emergence is always higher than the probability of reaching later stages, and so on (McKelvey and Lichtenstein, 2007; Lichtenstein and McKelvey, 2012).

Our synthetic view can be summarised as follows: by far the most frequent type of emergence appears as networks - McKelvey and Lichtenstein's (2007) Stage-1 emergence. Some of these emergent network configurations lead to the emergence of groups and group norms - their Stage-2. In certain cases, groups differentiate to more advantageously draw in environmental resources. This results in the beginnings of hierarchy (Massie, 1965; Salthe, 1993). This Stage-3 emergence solidifies the definition of 'qualitative novelty' - an emergent property is defined as 'different in kind' from its components (Blitz, 1992; Newman, 1996). Finally, a few hierarchies grow to become larger, i.e., large enough that new kinds of more complex coordinating structures and regulation processes must emerge if adaptive capability and efficiency are to be maintained - their Stage-4 emergence.

Measuring emergence in/of organisations. The key question answered by a PL based theory is, what is the relationship between emergent stages in a given dynamic system? In a formal sense, what is the likelihood, for example, that a network structure will emerge out of an assemblage of agents? What is the likelihood that a group will emerge out of that set of emergent networks? And how are these two events related? We recast this question in terms of probabilities of emergence, and suggest that the probability of a specific structural level emerging is a function of the emergence of some number of precursor stages (levels). 
Specifically, we hypothesise that the next stage of order emerges as a function of its probability times the joint probability of all prior stages emerging. For example, if the probability of each emergent level is 0.1 , the emergence of each successive level is one order of magnitude less likely than the one before. Thus, if we assume 1,000,000 emergent networks, PL theory predicts the emergence of 100,000 groups, 10,000 hierarchies, and so on. Of course, the actual probabilities are an empirical question. Based on this logic: ${ }^{4}$

Proposition 1: The likelihood that any subsequent stage will emerge is the joint probability of emergence of it times all prerequisite stages.

A visual representation of this idea is presented in Figure 1.

Figure 1 Emergence levels in/of organisations, and power law predictions of their frequency

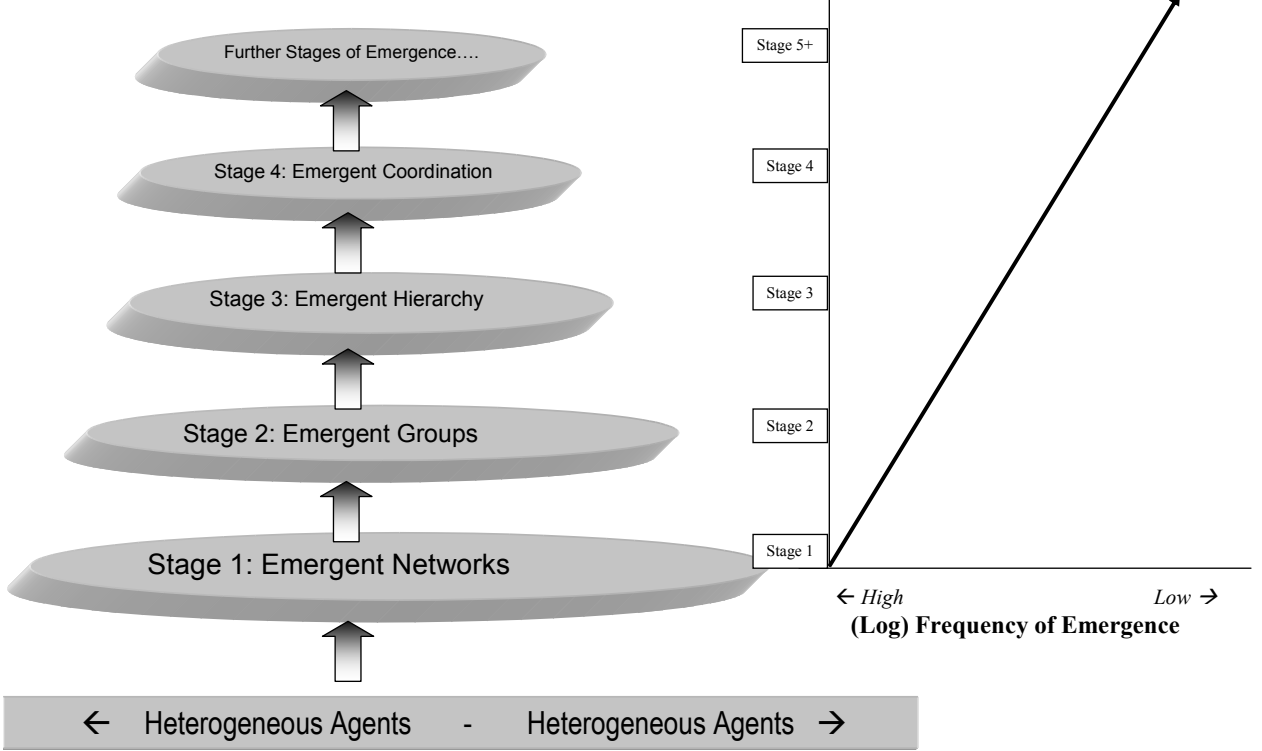

\subsection{Requisite fractal structure from underlying scale-free theory}

There are a number of scale-free theories we can draw upon to further solidify our notion that as further stages emerge, the organisation increasingly moves toward an internal fractal structure. This requires that we apply scale-free theories (drawn from various sciences) to organisations. This analysis was recently achieved by Andriani and McKelvey (2009), who list 15 scale-free theories can be applied to organisations. Here we mention only those that most clearly apply to the stages-of-emergence idea.

Hierarchical modularity. In his classic paper on the 'architecture of complexity', Simon (1962) offered a variant to the square/cube and connection-cost laws. He focused on 'nearly decomposable' systems, wherein modules are designed so as to minimise the connection-cost problem. The scale-free principle causing fractal structure is the idea that at each level in an organisation, agents attempt to minimise connection costs by designing toward nearly-autonomous modules. In this way the resulting structures are 'fractally' 
composed. Zimmerman and Hurst (1993, p.336) explain this link between self-organisation and fractal (self-similar) composition as follows:

"Fractal structures, then, can be thought of as the past tense or evidence of self-organizing systems. Fractals represent the discernible outcomes, or histories, that reveal the self-organizing propensities of dissipative structures."

Simon's canonical example compared two watchmakers making timepieces with 1,000 parts. In the approach used by Tempus, any interruption in the process of assembling all 1,000 pieces would cause the watch to fall to pieces, requiring him to reassemble it from scratch. In contrast, Hora designed the task into subassemblies of about ten elements each, each of which were put together in further sets of ten; all ten of the latter assemblies constituted the whole watch. We also have Adam Smith's 300 year old focus on division of labour. It was followed by contingency theory's discovery that differentiated subunits improved performance (Woodward, 1958; Burns and Stalker, 1961; Lawrence and Lorsch, 1967).

Following Simon's principle, and more recent research (Carneiro, 1987; Sanchez and Mahoney, 1996; Schilling, 2000; Shulman, 2004), we see that external competitors gain survival, growth, and competitive advantage by continually decomposing - i.e., self-organising - into modular subunits. For example, the CEO has four division presidents reporting; they each have four VPs; they each have four companies reporting, and so on. By this reasoning the most dangerous competitor firms surrounding a focal firm will be fractally structured. Many studies of competitive biological predator/prey ecosystems (we cite 19 here) show repeatedly that they have fractal structures (McMahon and Bonner, 1983; Schmidt-Nielsen, 1984; Aronson, 1992; Russell et al., 1992; Niklas, 1994; Tsuda, 1995; West et al., 1997; Solé et al., 2001; Cuddington and Yodzis, 2002; Haskell et al., 2002; Shinchi et al., 2002; Xiao et al., 2002; Hoddle, 2003; Liu and Chen, 2003; Ferguson, 2004; Laidre et al., 2004; Phillips et al., 2004; Tremblay et al., 2007; Sims et al., 2008).

Square/cube law. Dating back to Galileo ( 1638), the square/cube law is the oldest scale-free theory. In organisms, surfaces absorbing energy grow by the square, but the organism grows by the cube, resulting in an imbalance. In cauliflowers, the fractal structure is very visible - the structure, function, and causal dynamics are the same for the whole and continuing down from the largest to smallest florets. The fractal structure emerges to bring surface/volume back into balance.

Haire (1959) first applied it successfully to four firms. Levy and Donhowe (1962) confirmed his findings in 62 firms in eight industries. Stephan (1983) derives his application of the square-cube law to firms via 'time minimisation' theory. He defines organisational effectiveness in terms of time-minimisation. Employees dealing with people outside the firm are 'surface' employees - they bring in the resources from the environment. 'Volume' employees are those inside who produce and coordinate. The square-cube law reflects the most efficient ratio. In a different context, Carneiro (1987) applies the law to explain the upper bound on the size of villages. The law limits their size unless they develop what he terms 'structural complexity', where complexity grows at $2 / 3$ power of a village's population. Only by doing this do villages avoid splitting in two. Whereas Stephan's theory is in terms of a specific variable, time-minimisation, Carneiro's theory is more general, saying simply that social entities can increase in size only by building in structural complexity. In his data, for example, 100-person villages had ten 'complexity traits' where as 1,000-person villages had four to five times as many. 
Connection-cost law. ${ }^{5}$ While the square/cube law responds to the problem of creating more subunits so as to keep the surface/volume ratio constant as the system grows, the connection-cost law operates in reverse. Supposing modularity grows by the square, connectivity could increase by $n(n-1) / 2$, producing an imbalance between the gains from modularity vs. the cost of maintaining connectivity. Consequently organisms and organisations form fewer cells or modules so as to reduce the cost of connectivity. Here the fractal structure emerges so as to keep connection costs under control.

Organisms and organisations usually grow to copy with or take advantage of a demanding environment - resources, constraints, competitors; they gain economies of scale or even increasing returns to scale (Arthur, 1988). An entity can do this by growing in size, i.e., doubling, and then doubling again, and so on. While divisions increase by the square, however, their pair-wise connections, $c$, increase by the formula: $n(n-1) / 2$, where $n=\#$ of units; thus if $n=2,4,8,16,32,64$ then $c=1,6,28,120,496,4,032$. A module has to accomplish two things:

1 use energy in coping with its environment - it has to move, find resources, process what it intakes, accomplish various survival tasks (Kauffman, 1993), etc.

2 use energy in maintaining and using the pair-wise communications with other modules.

Because of the $n / c$ ratio, however, at some point the amount of energy going into intra-module communication significantly detracts from the module's ability to cope successfully with its environment. At this point the system recombines modules and divides into two macro units specialised in different tasks, bringing the over-communication problem back under control. The underlying cause of the PL is the basic $n / c$ relationship and the need to keep dividing to better cope with the environment but keep communication costs under control. Note that our suggested growth of $n$ is exponential, as is the growth of $c$. In real entities, the growth of the communication network could grow because of interactions, positive feedback, and contextually-caused bursts, leading to a PL signature rather than other kinds of skew distributions.

Self-organised criticality (SOC). Under constant tension of some kind (gravity, ecological balance, delivery of oxygen), some systems reach a critical state where they maintain stasis by preservative behaviours - such as Bak's famous sandpile avalanches, as well as forest fires, changing heartbeat rates, growth rates of firms, etc. - which vary in size of effect according to a PL (Bak et al., 1987; Drossel and Schwabl, 1992; Bak, 1996). Here the fractal is dynamic, whereby actions to cause change may be very small or of avalanche proportions.

Bak (1996) applied his SOC principle to economies, arguing that individual decisions are sticky like irregular sand grains, not like marbles. The result is that even though the tension between supply and demand builds, actions to reduce it are not of equal size and regularity. Consequently economies operate at or near the critical state. This shows up in the things like the price of cotton and many other economic realities described by Mandelbrot and Hudson (2004), consumer product sales (Moss, 2002; Sornette et al., 2004), entrepreneurial responses and results leading to different sized firms (Stanley et al., 1996), and stock-market price volatilities (Zhou and Sornette, 2002, 2003, Sornette and Zhou, 2006, Jondeau et al., 2007; Maskawa, 2007; Calvet and Fisher, 2008; Du and Ning, 2008; Eom et al., 2008; Kumar and Deo, 2009; Sornette and Woodard, 2009; Yan et al., 2010; McKelvey and Salmador Sanchez, 2011; McKelvey and Yalamova, 2011a, 
2011b; Yalamova and McKelvey, 2011) - all of which show PL signatures. The parallel to sand avalanches is clear: from gravity to supply/demand; from irregular sand grains to irregular consumer and managerial decision processes and outcomes, from biological SOC to firms' and stock market SOC, the results are similar: PL shaped avalanches vs. PL shaped economic events and changes. Embedded within the broader economic outcomes are individual human decision processes and consequent organisational dynamics.

Even more relevant here is the idea that SOC also applies to actions aimed at optimising the square/cube ratio, modularity vs. connection costs, or moves toward or away from Simon's nearly autonomous subunits. It is easy to see that either top-down managerial efforts or more self-organised, informal, autonomous, bottom-up efforts may resolve problems via many small, irregular steps or more rare major reorganisations, as shown by Thomas et al. $(2005,2012)$. In this case we have one kind of scale-free theory governing the operation of three others, or in other words, fractal dynamics upon fractal dynamics.

Least effort. Word frequency is a function of ease of usage by both speaker/writer and listener/reader; this gives rise to Zipf's (1949) (power) law. While his least-effort scalefree explanation is second only to the square/cube law in date or origin, and was originally applied to cities and language, it has very recently taken on a new life. Recent studies put new light on where we are most likely to find fractal design responses to external complexity and fractality.

Zipf's least-effort theory is now shown to apply only under changing circumstances. Ishikawa (2006) shows that PLs show up in firms where there is higher rate of job growth and change, but does not apply to large firms where growth is slow. Dahui et al. (2006) show that the distribution of firms in growth markets is a PL but in markets without growth it is not. Finally, Podobnik et al. (2006) find empirically - and test further with a computational model - that transition economies (e.g., Hungary, Russia, Slovenia, etc.), show the PL signature whereas stable economies do not. McKelvey (forthcoming) uses PLs to show how broken is the UK economy. From these new discoveries we conclude that the least effort scale-free theory applies, especially, to organisations, industries, and economies that are growing or are in transition.

Preferential attachment. Given newly arriving agents into a system, larger nodes with an enhanced propensity to attract agents will become disproportionately even larger, resulting in the PL signature (Yule, 1925; Barabási, 2002). This is otherwise known as the 'rich get richer' dynamic. If per chance the fractal structure of a system were seemingly to stabilise, preferential attachment is a scale-free dynamic that serves to disrupt all of the foregoing fractal structures.

This positive feedback process is most evident in the long demonstrated need for antitrust laws. The robber barons of the 19th century were notorious for using the resources they controlled so as to gain even more. It shows up in Arthur's (1994) focus on increasing returns - firms making profits can invest in things that make even more profits - Google is a good modern example. Preferential attraction appears in the development of the biotech industry (Powell et al., 2005). It shows up in the growth of airport hubs - larger hubs attract even more flights (Barrat et al., 2004; Guimerà and Amaral, 2004). Marketing and sales via the internet is very much a positive feedback process [Anderson, (2006), pp.15-17]. As nodes change in relative size, the fractal balancing process begins, whether square-cube or modules vs. connection costs. A modern example here are the various dynamics associated with the growth of Wal-Mart, 
such as the merger of Target and Sears and all the follow-on dynamics stemming from that.

Adaptive tension. As we described earlier, exogenous energy impositions tipping over the 1st critical value, $R_{C 1}$, cause emergent dissipative structures (Prigogine, 1955; Stauffer, 1985; Nicolis and Prigogine, 1989; Kauffman, 1993). These are new interaction groupings having some probability of showing a PL signature and fractal structure (Mantegna and Stanley, 2000; Sornette, 2006; Newman, 2005). Tension effects in general have the same SOC effect that gravity imposes on Bak's sandpiles.

Forcing adaptive tension above the 1st critical value instigates phase transitions. Jack Welch - Fortune magazine's 'Manager of the Century' - set the phase transition in motion at GE with his famous rule of 'Be \#1 or \#2 or [else]' [Tichy and Sherman, (1994), p.108]. Kotter (1996, pp.42) does it by 'pushing up the urgency level'. Collins (2001, p.65) forces the phase transition with his chapter title: 'confront the brutal facts'. $3 \mathrm{M}$ does it by insisting that $20 \%$ of annual revenues in each division be generated by new products developed over the past five years. This adaptive tension imposed by CEOs from the inside, sets positive feedback in motion, resulting in our stages of emergence - networks, groups, hierarchy, and then causal complexity (Lichtenstein, 2010). Of course, similar levels of externally imposed tension occur when new technologies, new markets, new competitors, or new political regimes appear. We all now see the tension imposed on firms trying to (or failing to) compete against Apple's iPhone and iPad.

Contagion bursts. Often, viruses are spread exponentially - each person coughs upon two others and the network expands geometrically by the square. But, changing rates of contagious flow of viruses, bacteria, stories, and metaphors, because of changing settings such as almost empty or very crowded rooms and airplanes, result in bursts of contagion or spreading via increased interactions; these bursts result in the PL signature (Taylor, 1984; Agar, 2005).

Baskin (2005) talks about feedback loops that occasionally spiral. In his view, a story is a simplification of a complex reality that spreads more easily or quickly. If the story confirms peoples' experience it is reinforced and then spreads more rapidly. In an organisation, if people tell their stories, ideas, etc. in meetings, as opposed to one-on-one conversations, and others also spread the story in groups, where story-telling-andlistening bursts can result that lead to the PL signature. A good story, thus, is like a virus that mutates from animal to human and becomes airborne and highly contagious. When the spread of a comment, story, or video spreads quickly on the Internet it is now described as 'going viral'. Given that contagious stories can be told to groups and even larger audiences, they can spread very rapidly. These, then, may become agents for reshaping the dynamics of an organisation, changing the preferential attachment dynamics, size of modules, levels of connections, and so on, such that the SOC process starts up to rebalance the fractal structure.

Interacting fractals. Many systems that are subjected to opposing regulatory pressures show PL-distributed variability. In physiology, for instance, heart rate and breathing are both subjected to the control of the sympathetic and parasympathetic nervous systems. The first tends to slow down heart beating, the second to accelerate it each has a different fractal dimension. This makes heartbeats multifractal (West, 2006). The fractal structures of species are based on their food web [S. Pimm quoted in Lewin, (1992), p.121], which is a function of the fractal structure of predators and niche resources (Preston, 1948; Pimm, 1982; Solé et al., 2001; West, 2006). 
In the business world, if predators (competitors) and niche resources (customers, suppliers, banks, etc.) and habitats (economic environments) are fractal, then large firms and/or industries that are subject to both sources of competitive pressure are likely multifractal. Stanley et al.'s (1996) study of ' .... all publicly traded manufacturing firms between 1975 and 1991' evidences this. They show firm size as a power law. It follows that most industry structures - competitors, firms in a 'target' industry, and resources also have to be fractally structured; if the parts aren't mostly fractal, the whole can't be.

Combination theory. Sometimes no single skew distribution - such as those mentioned above - is sufficient to set off a dramatic extreme event. For example, McKelvey and Yalamova (2011b) offer a history of the build-up to the financial crisis of 2007 and the follow-on Great Recession. They connect various scale-free theories to key historical developments, none of which by itself set off an equivalent to the Great Recession:

1 Phase transitions: the invention of derivatives in 1972, along with financial engineering, gave rise to dramatic new trading methods

2 Contagion bursts: as more and more traders started working for global banks, had international email and phone connections, and world economies became more and more connected, skew distributions in risk-taking became more frequent as traders quickly learned from each other

3 Preferential attachment: needless to say, in banking the 'rich get richer' effect came to dominate; successful traders and banks had growing influence in global financial trading; the networked influence of the rich dominated; bigger banks could buy up smaller banks (see also Battiston et al., 2012)

4 Spontaneous order creation: the Clinton and Bush presidential policies of making it easier for people to buy houses - by reducing the importance of credit scores and personal income statements - coupled with the prior invention of mortgage-backed securities both lowered the risk of buying a house while at the same time allowed banks to treat home values like monetary reserves against risk. As long as the housing bubble kept increasing, risk was minimised so loans based on mortgagebacked securities rapidly grew in volume

5 Combination theory: the collective interaction of non-normal, somewhat skewed distributions can create a more dramatically skewed distribution that ends up as a PL distribution with an extreme outcome at the end of one tail - such as the Great Recession.

While none of the first four scale-free dynamics in the foregoing list can be pointed to as the cause of the liquidity crisis, in combination they collectively gave rise to the Great Recession.

We have taken some effort to present a variety of scale-free theories, all of which apply to organisations. They not only apply one by one, but also in combination. The SOC fractal dynamic emerges as other fractal imbalances need to be rebalanced. While some fractals are designed to foster efficacious adaptation, other fractals are disruptive, thereby keeping the SOC dynamic continually operative. Our 'stage' fractals operate over time, showing emergence from agents to complex hierarchies. From this we see structural fractals as we work up from the bottom to top of organisations. From our Law of Requisite Fractality - based on our updating of Ashby's Law of Requisite Variety - we 
can formulate an additional three propositions calling for further research to confirm findings from econophysics (Stanley et al., 1996; Mantegna and Stanley, 2000; Axtell, 2001; Newman, 2005).

Proposition 2: The external industry complexity surrounding organisations is essentially fractal in both structure and dynamics.

Proposition 3: The law of requisite fractality therefore applies; firms that have completed efficacious internal adaptive fractal responses to their surrounding fractal competitive context will show improved performance.

By way of some preliminary evidence in support of Proposition 2, we did a PL analysis of recent data (shown in Table 2) on the software ecosystem surrounding Microsoft. As one can see, it appears as straight-line PL distribution in Figure 2 where we plot the numbers in a double-log graph. ${ }^{6}$ Except for the three largest firms down on the Y-axis, the figure shows a well-formed PL distribution. This indicates that the ecosystem surrounding Microsoft is well performing in part because, as Iansiti and Levien (2004) claim, it is fractal.

Table 2 Microsoft's ecosystem

\begin{tabular}{llll}
\hline Systems integrators & 7,752 & Unsegmented resellers & 290 \\
$\begin{array}{l}\text { Development services } \\
\text { companies }\end{array}$ & 5,747 & Media stores & 238 \\
Campus resellers & 4,743 & Mass merchants & 220 \\
Independent software vendors & 3,817 & Outbound software firms & 160 \\
Trainers & 2,717 & Computer superstores & 51 \\
Breadth value-added resellers & 2,580 & Application service provider & 50 \\
Small specialty firms & 2,252 & E-tailers & 46 \\
Top value-added resellers & 2,156 & Office superstores & 13 \\
Hosting service providers & 1,379 & General aggregators; warehouse club & 7,7 \\
Internet service providers & 1,253 & stores & Niche specialty stores; sub-distributors \\
Business consultants & 938 & Applications integrators & 6,6 \\
Software support companies & 675 & Microsoft direct resellers & 5 \\
Outbound hardware firms & 653 & Microsoft direct outlets & 2 \\
Consumer electronics & 467 & Network equip. and service providers & 1,1 \\
companies & &
\end{tabular}

Source: From Iansiti and Levien (2004, p.71)

One significant implication becomes apparent when we go beyond our initial, restrictive set of four stages, and focus more broadly on any set of hierarchically nested systems in a firm. For example, one might apply PL theory to the emergence of a new corporate venture by proposing a series of progressive stages, each being contingent to prior ones. A good example is provided by Brush et al. (2001), who show how the viability of a corporate venture depends on a build-up of increasingly complex resource combinations, from generic resources to capabilities to core competencies to strategic assets to unique advantage. According to our theory, the more consistently (across levels) the 'resource 
combination' approach is applied, the more likely the venture will emerge successfully. Similar claims could be made and empirically tested for new product development, alliance formation, and industry emergence. ${ }^{7}$

Figure 2 Ecosystem shown as a power law distribution

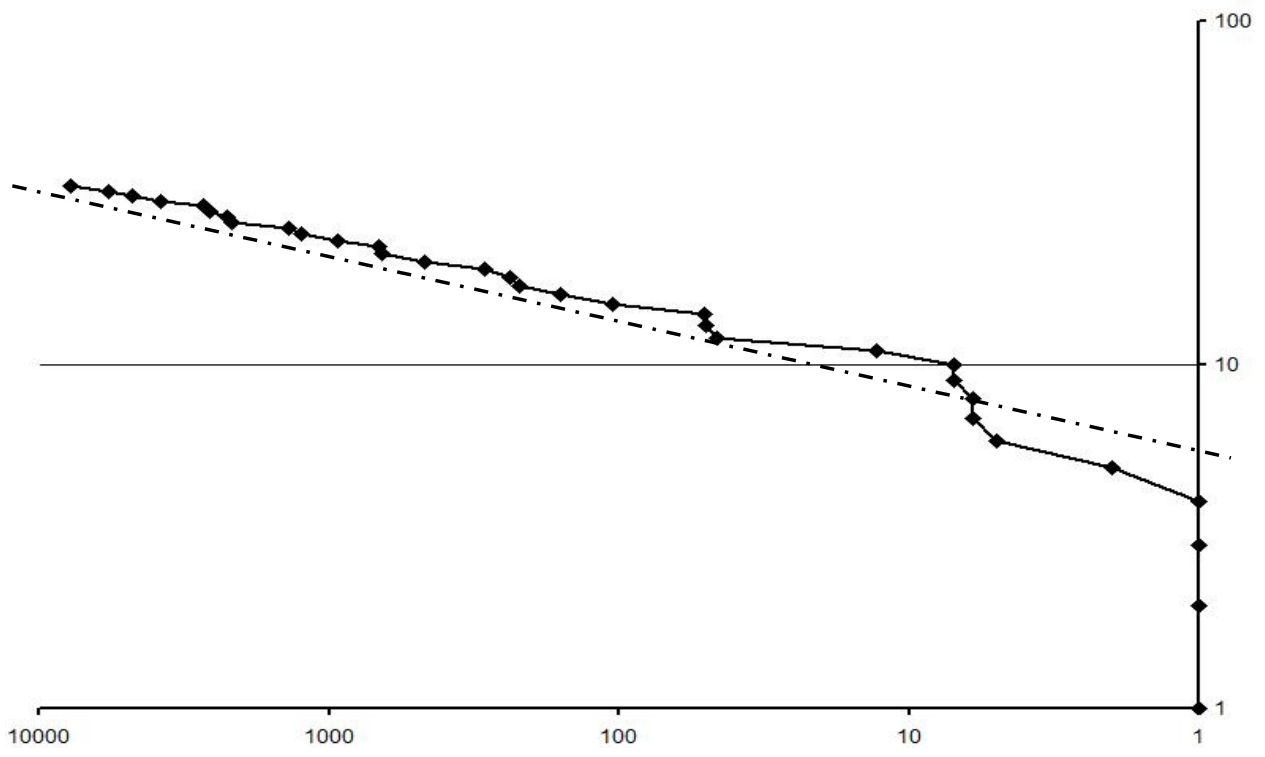

Note: Frequency of firms in each size of domain, from 7,752 down to 1

Building from the works of Iansiti and Levien (2004), Ishikawa (2006), Dahui et al. (2006), Podobnik et al. (2006), Glaser (2009) and McKelvey (forthcoming), it appears that positive working conditions of self-organised criticality (SOC) (Bak, 1996) at the ecosystem/industry level of analysis are indicated by PLs and fractal structures. Another recent indication of well working SOC is evidence that M\&A activity - which is the industry indicator of predator/prey activities - is also power-law distributed, i.e., fractal (Park et al., 2011). External requisite fractality calls for requisite fractality inside firms. But to get fractality inside a firm, it needs to have well-functioning SOC inside.

Given intra-firm SOC and consequent intra-firm fractals, firms require very little information to build up into complex multifractal structures. First, as noted above, fractal systems build via the recursive action of scale-free generative causes (several of which we have described), which become activated any time the required internal or environmental conditions prevail. If one considers that the complexity of the cardiovascular system, for example, defines all the information that can be captured in the DNA, then it becomes clear that a highly fractal entity such as the cardiovascular system can only be built via a co-construction process in which generative rules interact with imposing internal and environmental pressures and coevolutionary responses. One of the reasons why fractal systems are so pervasive is the fact that their construction requires little pre-existing information acting like a blueprint. They are emergent!

Our second reason goes directly to the 'it takes internal fractality to thwart external fractality' argument. West (2006) in Where Medicine Went Wrong, makes the point that a multifractal system is more robust than other systems because it can respond to a 
disturbance within the appropriate time scale. Suppose the disturbance is a dramatic complex shock to a complex firm; a multifractal system can react within the required time scale since it has multi-scale levels of response capability. Since the disturbance stems from the nested fractal structure of competitors within the firm's competitive environment - e.g., its industry or larger socio-economic and/or political context - the various parts of the firm's internal fractal system need to become efficaciously SOC so that the required or requisite internal levels (parts) of its multifractal structure get involved in reacting in parallel to the various external fractal layers giving rise to the complex disturbance. One of the features of mature systems in both organisms and organisations - especially 'bureaucratic' organizations - is the loss of this multiscale response capability. This suggests:

Proposition 4: Firms need well-functioning SOC inside to perform well and grow in an external competitive industry environment that is characterised by a fractal (and possibly multifractal) structure.

\section{Conclusions}

In his introductory essay in the Santa Fe Institute's 'founding anthology' (Pines, 1988), Nobel Laureate Murray Gell-Mann (1988) set the stage for some 31 disciplines coming together to focus on 'emergence' and 'deep simplicity'. More recently (2002), he translates 'deep simplicity' into scalability, and then elevates scalability to a scientific status equal to the traditional scientific focus on conservation of energy, law-like equations, and explanation via reductionism. So, based on this we now have two 'regularities' - law-like reductionism and scalability dynamics across levels - deserving the attention of scientific theorists and researchers.

Perhaps the three most far-reaching discoveries from the American School are:

1 the value of computational agent-based experiments for studying emergence

2 the widespread existence of PL effects characterising emergent structures

3 scale-free theory wherein seeming complexity reduces to simplicity (Casti, 1994;

Brock, 2000; Gell-Mann, 2002).

While the first of these discoveries has infused into organisation and management research, the last two remain largely unexplored. ${ }^{8}$

With the goal of developing a PL theory for management, McKelvey and Lichtenstein (2007) define emergence as a multi-dimensional construct and search the computational modelling literature to see what types or levels of organisational emergence have been created through the technology of computational experiments. They also find that true bottom-up emergence generates a very large number of emergent networks, a much smaller number of emergent groups and hierarchies, and few increasingly intricate emergent causal hierarchical structures. European dissipative structures theory explains what gives rise to these 'stages of emergence'. Using US complexity theory, we propose that these stages have a PL relationship with each other. We then expand our analysis to consider the similarity of drivers across stages, and then present a new Law of Requisite Fractality applied to organisations. Finally we signify 
several organisational implications arising from our requisite fractality theory in the form of propositions.

Though we cite 19 biological research articles/books showing evidence of fractal ecological systems and, thus, evidence of requisite fractality in biology, this is a largely un-researched subject in organisation science. We show the software ecosystem to be fractal; Axtell (2001) shows all US firms to be fractal; Ishikawa (2006) shows that some SIC two-digit industry groupings are fractal; Stanley et al. (1996) offer some evidence that the internal structure and growth and decline of firms is fractal; Glaser (2009) shows that the market capitalisations of firms in various industries from 1930 to 2008 are PL distributed, and Chou and Keane (2009) show PL distributions for four internet industries; but on balance this is pretty sketchy evidence. Our propositions specifically, and requisite fractality in general, are surely in need of further research.

Overall, our greatest potential contribution is to provide a more explicit complexity theory of emergence. More than reviewing the science of complexity, we claim to have developed new theory through our explanation for how and why emergence happens, in conjunction with a description of what actually emerges within and across ontological levels of organising (Whetten, 1989). The relevance of such a theory is clear, given the critical importance of understanding emergence in this age of intangible assets, a digitised knowledge-based economy, globalisation, the sustainability imperative and the increasing impact of emerging ventures and emerging markets. In sum, our formulation of a requisite-fractality complexity theory of emergence can provide a new foundation for management scholars researching emergence across many levels, as well as a powerful set of conceptual tools for improving the quality of management in 21 st century organisations.

\section{References}

Abbott, A. (1988) 'Transcending general linear reality', Sociological Theory, Vol. 6, No. 5, pp.169-186.

Adams, R.N. (1988) The Eighth Day: Social Evolution as the Self-Organization of Energy, University of Texas, Austin, TX.

Adler, P. and Obstfeld, D. (2006) 'The role of affect in creative projects and exploratory search', Industrial and Corporate Change, Vol. 16, No. 1, pp.19-50.

Agar, M. (2005) 'We have met the other and were all nonlinear: ethnography as a nonlinear dynamic system', Complexity, Vol. 10, No. 2, pp.16-24.

Albert, L., Jeong, H. and Barabási, A.L. (2000) 'Error and attack tolerance of complex networks', Nature, Vol. 406, No. 27, pp.378-382.

Allen, P.M. (1975) 'Darwinian evolution and a predator-prey ecology', Bulletin of Mathematics and Biology, Vol. 37, No. 4, pp.389-405.

Allen, P.M. (1988) 'Evolution: why the whole is greater than the sum of its parts', in Wolff, W., Soeder, C-J. and Drepper, F.R. (Eds.): Ecodynamics, pp.2-30, Springer-Verlag, Berlin.

Allen, P.M. (1993) 'Evolution: persistent ignorance from continual learning', in Day, R.H. and Chen, P. (Eds.): Nonlinear Dynamics \& Evolutionary Economics, pp.101-112, Oxford University Press, Oxford, UK.

Allen, P.M. (1994) 'Evolutionary complex systems: models of technology change', Leydesdorff, L. and van den Besselaar, P. (Eds.): Chaos and Economic Theory, pp.1-17, Pinter, London.

Allen, P.M. (2001) 'A complex systems approach to learning, adaptive networks', International Journal of Innovation Management, Vol. 5, No. 2, pp.149-180.

Anderson, C. (2006) The Long Tail, Random House Business Books, London. 
Anderson, P. (1999) 'Complexity theory and organization science', Organization Science, Vol. 10, No. 3, pp.216-232.

Anderson, P., Meyer, A., Eisenhardt, K., Carley, K. and Pettigrew, A. (1999) 'Introduction to the special issue: applications of complexity theory to organization science', Organization Science, Vol. 10, No. 3, pp.233-236.

Anderson, P.W., Arrow, K.J. and Pines, D. (Eds.) (1988) 'The economy as an evolving complex system', Proceedings of the Santa Fe Institute, Vol. 5, Addison-Wesley, Reading, MA.

Andriani, P. and McKelvey, B. (2007) 'Beyond Gaussian averages: redirecting organization science toward extreme events and power laws', Journal of International Business Studies, Vol. 38, No. 7, pp.1212-1230.

Andriani, P. and McKelvey, B. (2009) 'From Gaussian to Paretian thinking: causes and implications of power laws in organizations', Organization Science, Vol. 20, No. 6, pp.1053-1071.

Andriani, P. and McKelvey, B. (2011) 'From skew distributions to power law science', in Allen. P., Maguire, S. and McKelvey, B. (Eds.): Handbook of Complexity and Management, pp.254-273, Sage, London.

Aronson, R.B. (1992) 'Biology of a scale-independent predator-prey interaction', Marine Ecology Progress Series, Vol. 89, pp.1-13.

Arthur, W.B. (1988) 'Self-reinforcing mechanisms in economics', in Anderson, P. Arrow, K.J. and Pines, D. (Eds.): The Economy as an Evolving Complex System, pp.9-31, Addison-Wesley, Reading, MA.

Arthur, W.B. (1990) 'Positive feedback in the economy', Scientific American, Vol. 262, No. 2, pp.92-99.

Arthur, W.B. (1994) Increasing Returns and Path Dependence in the Economy, University of Michigan Press, Ann Arbor, MI.

Arthur, W.B., Durlauf, S.N. and Lane, D.A. (Eds.) (1997) 'The economy as an evolving complex system II', Proceedings of the Santa Fe Institute, Vol. 27, Addison-Wesley, Reading, MA.

Ashby, W.R. (1956) An Introduction to Cybernetics, Chapman \& Hall, London.

Ashby, W.R. (1962) 'Principles of the self-organizing system', in von Foerster, H. and Zopf, G.W. (Eds.): Principles of Self-Organization, pp.255-278, Pergamon, New York.

Ashmos, D. and Huber, G. (1987) 'The system paradigm in organization theory: correcting the record and suggesting the future', Academy of Management Review, Vol. 12, No. 4, pp.607-621.

Auerbach, F. (1913) 'Das Gesetz der Bevolkerungskoncentration', Petermanns Geographische Mitteilungen, Vol. 59, No. 1, pp.74-76.

Axelrod, R. and Bennett, D.S. (1993) 'A landscape theory of aggregation', British Journal of Political Science, Vol. 23, No. 2, pp.211-233.

Axtell, R.L. (2001) 'Zipf distribution of U.S. firm sizes', Science, Vol. 293, No. 5536, pp.1818-1820.

Bak, P. (1996) How Nature Works: The Science of Self-organized Criticality, Copernicus, New York.

Bak, P. and Chen, K. (1991) 'Self-organized criticality', Scientific American, Vol. 264, No. 1, pp.46-53.

Bak, P., Tang, C. and Wiesenfeld, K. (1987) 'Self-organized criticality: an explanation of 1/f noise', Physical Review Letters, Vol. 59, No. 4, pp.381-384.

Baldwin, J.M. (1896) 'A new factor in evolution', American Naturalist, Vol. 30, No. 354, pp.441-451, pp.536-553.

Baldwin, J.M. (1902) Development and Evolution, MacMillan, London.

Barabási, A-L. (2002) Linked: The New Science of Networks, Perseus Publishing, Cambridge, MA.

Barrat, A., Barthélemy, M. and Vespignani, A. (2004) 'Weighted evolving networks: coupling topology and weight dynamics', Physical Review Letters, Vol. 92, No. 22, pp.228701:1-4. 
Bartunek, J., Gordon, J. and Weathersby, R. (1983) 'Developing 'complicated' understanding in administrators', Academy of Management Review, Vol. 8, No. 2, pp.273-284.

Baryshev, Y. and Teerikorpi, P. (2002) Discovery of Cosmic Fractals, World Scientific, Hackensack, NJ.

Baskin, K. (2005) 'Complexity, stories and knowing', Emergence: Complexity \& Organisation, Vol. 7, No. 2, pp.32-40.

Bateson, G. (1972) Steps to an Ecology of Mind, Ballantine Books, New York.

Battiston, S., Puliga, M., Kaushik, R., Tasca, P. and Galdarelli, G. (2012) 'DebtRank: too central to fail? Financial networks, the FED and systemic risk', Scientific Reports, Vol. 2, No. 541, pp.1-6, DOI:10.1038/srep00541.

Binks, M. and Vale, P. (1990) Entrepreneurship and Economic Change, McGraw-Hill, London.

Blitz, D. (1992) Emergent Evolution: Qualitative Novelty and the Levels of Reality, Kluwer Academic, Boston, MA.

Boisot, M. and McKelvey, B. (2010) 'Integrating modernist and postmodernist perspectives on organizations: a complexity science bridge', Academy of Management Review, Vol. 35, No. 3, pp.415-433.

Boisot, M. and McKelvey, B. (2012) 'Extreme outcomes, connectivity, and power laws: toward an econophysics of organization', in Child, J. and Ihrig, M. (Eds.): Knowledge and the Study of Organizations and Management: Building on the Work of Max Boisot, Oxford University Press, Oxford, UK.

Boulding, K.E. (1956a) 'General systems theory - the skeleton of science', Management Science, Vol. 2, No. 3, pp.197-208.

Boulding, K.E. (1956b) The Image: Knowledge in Life and Society, University of Michigan Press, Ann Arbor, MI.

Boulding, K.E. (1988) The World as a Total System, Sage, Thousand Oaks, CA.

Brock, W.A. (2000) 'Some Santa Fe scenery', in Colander, D. (Ed.): The Complexity Vision and the Teaching of Economics, pp.29-49, Edward Elgar, Cheltenham, UK.

Brown, J.S. and Duguid, P. (1991) 'Organizational learning and communities-of-practice: toward a unified view of working, learning, and innovation', Organization Science, Vol. 2, No. 1, pp.40-57.

Brown, S.L. and Eisenhardt, K.M. (1997) 'The art of continuous change: linking complexity theory and time-based evolution in relentlessly shifting organizations', Administrative Science Quarterly, Vol. 42, No. 1, pp.1-34.

Brush, C., Greene, P. and Hart, M. (2001) 'From initial idea to unique advantage: the entrepreneurial challenge of constructing a resource base', Academy of Management Executive, Vol. 15, No. 1, pp.64-78.

Burns, T. and Stalker, G.M. (1961) The Management of Innovation, Tavistock, London.

Calvet, L.E. and Fisher, A.J. (2008) Multifractal Volatility: Theory, Forecasting, and Pricing, Academic Press, Burlington, MA.

Carley, K.M. (1990) 'Group stability: a socio-cognitive approach', in Lawler, B.M.E., Ridgeway, C. and Walker, H. (Eds.): Advances in Group Processes, Vol. 7, pp.1-44, J.A.I Press, Stamford, CT.

Carley, K.M. (1999) 'On the evolution of social and organizational networks', in Andrews, S.B. and Knoke, D. (Eds.): Research in the Sociology of Organizations, Vol. 16, pp.3-30, JAI Press, Stamford, CT.

Carley, K.M. and Svoboda, D.M. (1996) 'Modeling organizational adaptation as a simulated annealing process', Sociological Methods and Research, Vol. 25, No. 1, pp.138-168.

Carneiro, R.L. (1987) 'The evolution of complexity in human societies and its mathematical expression', International Journal of Comparative Sociology, Vol. 28, Nos. 3-4, pp.111-128.

Casti, J.L. (1994) Complexification: Explaining a Paradoxical World through the Science of Surprise, HarperPerennial, New York. 
Chaisson, E.J. (2001) Cosmic Evolution: The Rise of Complexity in Nature, Harvard University Press, Cambridge, MA.

Cheng, Y. and Van de Ven, A. (1996) 'The innovation journey: order out of chaos?', Organization Science, Vol. 6, No. 6, pp.593-614.

Chiles, T., Meyer, A. and Hench, T. (2004) 'Organizational emergence: the origin and transformation of Branson, Missouri's musical theatres', Organization Science, Vol. 15, No. 5, pp.499-520.

Chou, L. and Keane, C. (2009) 'How the internet works: inspired by Per Bak', Working paper, UCLA Anderson School of Management, Los Angeles, CA.

Cohen, M. (1999) 'Commentary on the organization science special issue on complexity', Organization Science, Vol. 10, No. 3, pp.373-376.

Colbert, B. (2004) 'The complex resource-based view: implications for theory and practice in strategic human resource management', Academy of Management Review, Vol. 29, No. 3, pp.341-358.

Collins, J. (2001) Good to Great: Why Some Companies Make the Leap and Others Don't, Harper Business, New York.

Cowan, G., Pines, D. and Meltzer, D. (Eds.) (1994) 'Complexity: metaphors, models, and reality', Proceedings of the Santa Fe Institute, Vol. 19, Addison-Wesley, Reading, MA.

Crutchfield, J. (1994) 'Is anything ever new? Considering emergence', in Cowan, G., Pines, D. and Meltzer, D. (Eds.): Complexity: Metaphors, Models, and Realty, pp.515-537, Addison-Wesley, Reading, MA.

Csanyi, V. and Kampis, G. (1985) 'Autogenesis: evolution of replicative systems', Journal of Theoretical Biology, Vol. 114, No. 2, pp.303-321.

Cuddington, K. and Yodzis, P. (2002) 'Predator-prey dynamics and movement in fractal environments', American Naturalist, Vol. 160, No. 1, pp.119-134.

Dahui, W., Li, Z. and Zengru, D. (2006) 'Bipartite produce-consumer networks and the size distribution of firms', Physica A, Vol. 363, No. 2, pp.359-366.

Darwin, C. (1859/1964) On the Origin of Species by Means of Natural Selection, Murray, London, [a Facsimile of the 1st ed. with an Introduction by E. Mayr [Harvard University Press, Cambridge, MA)].

De Vany, A. (2004) Hollywood Economics: How Extreme Uncertainty Shapes the Film Industry, Routledge, New York.

Dosi, G. and Fagiolo, G. (1998) 'Exploring the unknown: on entrepreneurship, coordination and innovation-driven growth', in Lesourne, J. and Orléan, A. (Eds.): Advances in Self-Organization and Evolutionary Economics, pp.308-352, Economica, London.

Drazin, R. and Sandelands, L. (1992) 'Autogenesis: a perspective on the process of organizing', Organizational Science, Vol. 3, No. 2, pp.230-249.

Drossel, B. and Schwabl, F. (1992) 'Self-organized criticality in a forest-fire model', Physica A, Vol. 69, Nos. 1-4, pp.47-50.

Du, G. and Ning, X. (2008) 'Multifractal properties of Chinese stock market in Shanghai', Physica $A$, Vol. 387, No. 1, pp.261-260.

Dyke, C. (1988) 'Cities as dissipative structures', in Weber, B.H., Depew, D.J. and Smith, J.D. (Eds.): Entropy, Information and Evolution: New Perspectives on Physical and Biological Evolution, pp.355-367, MIT Press, Cambridge, MA.

Eldredge, N. and Gould, S.J. (1972) 'Punctuated equilibrium: an alternative to phyletic gradualism', in Schopf, T.J.M. (Ed.): Models in Paleobiology, pp.82-115, Freeman Cooper, San Francisco.

Eom, C., Choi, S., Oh, G. and Jung, W-S. (2008) 'Hurst exponent and prediction based on weak-form efficient market hypothesis of stock markets', Physica A, Vol. 387, No. 18, pp.4630-4636.

Epstein, J.M. and Axtell, R. (1996) Growing Artificial Societies: Social Science from the Bottom $U p$, MIT Press, Cambridge, MA. 
Ferguson, S.H. (2004) 'Influence of edge on predator-prey distribution and abundance', Acta Oecologica, Vol. 25, Nos. 1-2, pp.111-117.

Fisher, R.A. (1930) The Genetical Theory of Natural Selection, Clarendon, Oxford, UK.

Fleming, L. and Sorenson, O. (2001) 'Technology as a complex adaptive system', Research Policy, Vol. 30, No. 7, pp.1019-1039.

Foster, J. (2000) 'Competitive selection, self-organization and Joseph A. Schumpeter', Journal of Evolutionary Economics, Vol. 10, No. 3, pp.311-328.

Frederick, W. (1998) 'Creatures, corporations, communities, chaos and complexity', Business and Society, Vol. 37, No. 4, pp.358-389.

Fritz, R. (1989) The Path of Least Resistance, Fawcett Columbine, New York.

Gartner, W. (1985) 'A conceptual framework for describing the phenomonon of new venture creation', Academy of Management Review, Vol. 10, No. 4, pp.696-706.

Gartner, W., Bird, B. and Starr, J. (1992) 'Acting as if: differentiating entrepreneurial from organizational behavior', Entrepreneurship Theory and Practice, Vol. 16, No. 3, pp.13-30.

Gavetti, G. and Levinthal, D.A. (2000) 'Looking forward and looking backward: cognitive and experiential search', Administrative Science Quarterly, Vol. 45, No. 1, pp.113-137.

Gell-Mann, M. (1988) 'The concept of the institute', in Pines, D. (Ed.): Emerging Syntheses in Science, Proceedings of the Founding Workshops of the Santa Fe Institute, Vol. 1, pp.1-15, Addison-Wesley, Redwood City, CA.

Gell-Mann, M. (1994) The Quark and the Jaguar: Adventures in the Simple and the Complex, Freeman, New York.

Gell-Mann, M. (2002) 'What is complexity?', in Curzio, A.Q. and Fortis, M. (Eds.): Complexity and Industrial Clusters, pp.13-24, Physica-Verlag, Heidelberg, Germany.

Getling, A. and Brausch, O. (2003) 'Cellular flow patterns and their evolution scenarios in three-dimensional Rayleigh-Benard convection', Physical Review E, Vol. 67, No. 4, pp.046313-046317.

Glaser, P. (2009) 'Fitness and inequality in an increasing returns world: applying the tools of complexity economics to study the changing distribution of US stock market capitalizations from 1930 to 2008', Working paper, UCLA Anderson School of Management, Los Angeles, CA.

Goldstein, J. (1988) 'A far-from-equilibrium systems approach to resistance to change', Organizational Dynamics, Vol. 17, No. 2, pp.16-26.

Guimerà, R. and Amaral, L.A.N. (2004) 'Modeling the world-wide airport network', European Physical Journal B, Vol. 38, No. 2, pp.381-385.

Haire, M. (1959) 'Biological models and empirical histories of the growth of organizations', in Haire, M. (Ed.): Modern Organization Theory, pp.272-306, Wiley, New York.

Halal, W.E. and Taylor, K.B. (1999) 21st Century Economics: Perspectives of Socioeconomics for a Changing World, Macmillan, New York.

Haskell, J.H., Ritchie, M.E. and Olff, H. (2002) 'Fractal geometry predicts varying body size scaling relationships for mammal and bird home ranges', Nature (letters), Vol. 418, No. 6897, pp.527-530.

Hoddle, M.S. (2003) 'The effect of prey species and environmental complexity on the functional response of Franklinothrips orizabensis: a test of the fractal foraging model', Ecological Entomology, Vol. 28, No. 3, pp.309-318.

Holland, J.H. (1988) 'The global economy as an adaptive system', in Anderson, P.W., Arrow, K.J. and Pines, D. (Eds.): The Economy as an Evolving Complex System, pp.117-124, Addison-Wesley, Reading, MA.

Holland, J.H. (1995) Hidden Order, Addison-Wesley, Reading, MA.

Holland, J.H. (1998) Emergence: From Chaos to Order, Perseus, Cambridge, MA.

Homans, G.C. (1950) The Human Group, Harcourt, New York. 
Iansiti, M. and Levien, R. (2004) 'Strategy as ecology', Harvard Business Review, Vol. 84, No. 3, pp.68-78.

Ishikawa, A. (2006) 'Pareto index induced from the scale of companies', Physica A, Vol. 363, No. 2, pp.367-376.

Jondeau, E., Poon, S-H. and Rockinger, M. (2007) Financial Modeling Under Non-Gaussian Distributions, Springer-Verlag, London.

Kauffman, S.A. (1993) The Origins of Order: Self-organization and Selection in Evolution, Oxford University Press, New York.

Kaye, B. (1993) Chaos \& Complexity, VCH, New York.

Kelso, J.A.S., Ding, M. and Schöner, G. (1992) 'Dynamic pattern formation: a primer', in Mittenthal, J.E. and Baskin, A.B. (Eds.): Principles of Organization in Organisms, Proceedings of the Santa Fe Institute, Vol. 13, pp.397-439, Addison-Wesley, Reading, MA.

Kolmogorov, Á.N. (1941) 'Uher das logarithmisch Normale Verteilungsgesetz der Dimensionen der Teilchen hei Zerstuckelung', Commits Rendus (DoLlady) de L'Academie des Sciences de l'URSS, Vol. 31, pp.99-101 [cited in West, B.J. and Deering, B. (1995) The Lure of Modern Science: Fractal Thinking, World Scientific, Singapore].

Kotter, J.P. (1996) Leading Change, Harvard Business School Press, Boston, MA.

Krugman, P. (1996) The Self-Organizing Economy, Bradford Press, Cambridge, MA.

Kumar, S. and Deo, N. (2009) 'Multifractal properties of the Indian financial market', Physica A, Vol. 388, No. 8, pp.1593-1602.

Laidre, K.L., Heide-Jorgensen, M.P., Logsdon, M.L., Hobbs, R.C., Dietz, R. and Van Blaricom, G.R. (2004) 'Fractal analysis of Narwhal space use patterns', Zoology, Vol. 107, No. 1, pp.3-11.

Lave, J. and Wenger, E. (1991) Situated Learning: Legitimate Peripheral Participation, Cambridge University Press, Cambridge, UK.

Lawrence, P.R. and Lorsch, J.W. (1967) Organization and Environment, Harvard Business School Press, Boston, MA.

Lenox, M., Rockart, S. and Lewin, A.Y. (2006) 'Interdependency, competition and the distribution of firm and industry profits', Management Science, Vol. 52, No. 5, pp.757-772.

Lesourne, J. and Orléan, A. (Eds.) (1998) Advances in Self-organization and Evolutionary Economics, Economica, London.

Levinthal, D. and Posen, H.E. (2007) 'Myopia of selection: does organizational adaptation limit the efficacy of population selection?', Administrative Science Quarterly, Vol. 52, No. 4, pp.586-620.

Levinthal, D.A. (1991) 'Organizational adaptation and environmental selection-interrelated processes of change', Organization Science, Vol. 2, No. 1, pp.140-145.

Levinthal, D.A. (1997) 'Adaptation on rugged landscapes', Management Science, Vol. 43, No. 7, pp.934-950.

Levinthal, D.A. and Warglien, M. (1999) 'Landscape design: designing for local action in complex worlds', Organization Science, Vol. 10, No. 3, pp.342-357.

Levy, S. and Donhowe, G. (1962) 'Explanations of a biological model of industrial organization', Journal of Business, Vol. 35, No. 4, pp.335-342.

Lewes, G.H. (1877) The Physical Basis of Mind: Being the Second Series of Problems of Life and Mind, J.R. Osgood, Boston.

Lewin, R. (1992) Complexity: Life at the Edge of Chaos, University of Chicago Press, Chicago, IL, (2nd ed. published in 1999).

Lichtenstein, B. (2000) 'Emergence as a process of self-organizing: new assumptions and insights from the study of nonlinear dynamic systems', Journal of Organizational Change Management, Vol. 13, No. 6, pp.526-544.

Lichtenstein, B. (2010) 'Moving far from far-from-equilibrium: opportunity tension as the driver of emergence', Emergence: Complexity and Organization, Vol. 11, No. 4, pp.15-25. 
Lichtenstein, B. and Plowman, D. (2009) 'The leadership of emergence: a complex systems leadership theory of emergence at successive organizational levels', The Leadership Quarterly, Vol. 20, No. 4, pp.617-630.

Lichtenstein, B., Carter, N., Dooley, K. and Gartner, W. (2007) 'Complexity dynamics of nascent entrepreneurship', Journal of Business Venturing, Vol. 22, No. 2, pp.236-261.

Lichtenstein, B.B. and McKelvey, B. (2012) 'Four types of emergence: a typology of complexity and its implications for a science of management', International Journal of Complexity In Leadership \& Management, Vol. 1, No. 4, pp.339-378.

Liu, X. and Chen, L. (2003) 'Complex dynamics of Holling type II Lotka-Volterra predator-prey system with impulsive perturbations on the predator', Chaos, Solitons and Fractals, Vol. 16, No. 2, pp.311-320.

MacIntosh, R. and MacLean, D. (1999) 'Conditioned emergence: a dissipative structures approach to transformation', Strategic Management Journal, Vol. 20, No. 4, pp.297-316.

Maguire, S. and McKelvey, B. (1999) 'Complexity and management: moving from fad to firm foundations', Emergence, Vol. 1, No. 2, pp.19-61.

Maguire, S., Hardy, C. and Lawrence, T. (2004) 'Institutional entrepreneurship in emerging fields: HIV/AIDS treatment advocacy in Canada', Academy of Management Journal, Vol. 47, No. 5 , pp.657-680.

Maguire, S., McKelvey, B., Mirabeau, L. and Öztas, N. (2006) 'Organizational complexity science', in Clegg, S., Hardy, C., Lawrence, T. and Nord, W.T. (Eds.): Handbook of Organizational Studies, Sage, Thousand Oaks, CA.

Mainzer, K. (1994) Thinking in Complexity: The Complex Dynamics of Matter, Mind, and Mankind, Springer-Verlag, New York [5th ed. published in 2007].

Malerba, F., Nelson, R., Orsenigo, L. and Winter, S. (1999). "History-friendly' models of industry evolution: the computer industry', Industrial and Corporate Change, Vol. 8, No. 1, pp.3-40.

Malnight, T. (2001) 'Emerging structural patterns within multinational corporations: toward process-based structures', Academy of Management Journal, Vol. 44, No. 6, pp.1187-1210.

Mandelbrot, B.B. (1975) Les Objets Fractals: Forme, Hasard et Dimension, Flammarion, Paris.

Mandelbrot, B.B. (1982) The Fractal Geometry of Nature, Freeman, New York.

Mandelbrot, B.B. and Hudson, R.L. (2004) The (Mis)Behavior of Markets: A Fractal View of Risk, Ruin, and Reward, Basic Books, New York.

Mantegna, R.N. and Stanley, H.E. (2000) An Introduction to Econophysics: Correlations and Complexity in Finance, Cambridge University Press, Cambridge, UK.

Marion, R. (1999) The Edge of Organization: Chaos and Complexity Theories of Formal Social Organization, Sage, Thousand Oaks, CA.

Maskawa, J. (2007) 'Stock price fluctuations and the mimetic behaviors of traders', Physica A, Vol. 382, No. 1, pp.172-178.

Massie, J.L. (1965) 'Management theory', in March, J.G. (Ed.): Handbook of Organizations, pp.387-422, Rand McNally, Chicago, Il.

Maturana, H.R. and Varela, F.J. (1980) Autopoiesis and Cognition, Reidel, Dordrecht, The Netherlands.

Maturana, H.R. and Varela, F.J. (1987) The Tree of Knowledge, Shambhala Publications, Boston, MA.

McKelvey, B. (1997) 'Quasi-natural organization science', Organization Science, Vol. 8, No. 4, pp.251-380.

McKelvey, B. (1999) 'Complexity theory in organization science: seizing the promise or becoming a fad?', Emergence, Vol. 1, No. 1, pp.5-32.

McKelvey, B. (2004) 'Toward a 0th law of thermodynamics: order-creation complexity dynamics from physics and biology to bioeconomics', Journal of Bioeconomics, Vol. 6, No. 1, pp.65-96. 
McKelvey, B. (2008) 'Emergent strategy via complexity leadership: using complexity science and adaptive tension to build distributed intelligence', in Uhl-Bien, M. and Marion, R. (Eds.): Complexity and Leadership: Part I: Conceptual Foundations, pp.225-268, Information Age Publishing, Charlotte, NC.

McKelvey, B. (forthcoming) 'Fixing the UK's economy', in McGlade, J., Strathern, M. and Richardson, K. (Eds.): Complexity in Human and Natural Systems, ISCE Publishing, Litchfield Park, AZ.

McKelvey, B. and Andriani, P. (2010) 'Using scale-free theory from complexity science to better manage risk', Risk Management, An International Journal, Vol. 12, No. 1, pp.54-82.

McKelvey, B. and Boisot, M. (2009) 'Redefining strategic foresight: 'Fast' and 'Far' sight via complexity science', in Costanzo, L. and MacKay, B. (Eds.): Handbook of Research on Strategy and Foresight, pp.15-47, Edward Elgar, Cheltenham, UK.

McKelvey, B. and Lichtenstein, B.B. (2007) 'Leadership in four stages of emergence', Hazy, J.K., Goldstein, J. and Lichtenstein, B.B. (Eds.): Complex Systems Leadership Theory, pp.93-107, ISCE Publishing Company, Boston, MA.

McKelvey, B. and Salmador Sanchez, M.P. (2011) 'Explaining the 2007 bank liquidity crisis: lessons from complexity science \& econophysics', Working paper, UCLA Management School, Los Angeles, CA.

McKelvey, B. and Yalamova, R. (2011a) 'Introduction to econophysics: correlated trader behaviours, bubbles and crashes, scalability dynamics, power laws and scale-free theories', in Sundström, G. and Hollnagel, E. (Eds.): Governance and Control of Financial Systems: A Resilience Engineering Perspective, Ch. 4, pp.27-36. Ashgate, Farnham, UK.

McKelvey, B. and Yalamova, R. (2011b) 'The build-up to the 2007 liquidity crisis: an example of scalability dynamics in action', in Sundström, G. and Hollnagel, E. (Eds.): Governance and Control, Ch. 5, pp.41-54, Ashgate, Farnham, UK.

McMahon, T.A. and Bonner, J.T. (1983) On Size and Life, Scientific American Library, New York.

Meyer, A.D., Gaba, V. and Colwell, K.A. (2005) 'Organizing far from equilibrium: non-linear change in organizational fields', Organization Science, Vol. 16, No. 5, pp.456-473.

Mihata, K. (1997) 'The persistence of emergence', in Eve, R.A., Horsfall, S. and Lee, M.E. (Eds.): Chaos, Complexity, and Sociology, pp.30-38, Sage, Thousand Oaks, CA.

Miller, J.G. (1978) Living Systems, McGraw-Hill, New York.

Montroll, E.W. and Badger, W.W. (1974) Introduction to Quantitative Aspects of Social Phenomena, Gordon and Breach, New York.

Morel, B. and Ramanujam, R. (1999) 'Through the looking glass of complexity: the dynamics of organizations as adaptive and evolving systems', Organization Science, Vol. 10, No. 3, pp.278-293.

Morgan, C.L. (1923) Emergent Evolution, Williams \& Norgate, London.

Moss, S. (2002) 'Policy analysis from first principles', Proceedings of the National Academy of Sciences, 99 (Suppl. 3), pp.7267-7274.

Newman, D. (1996) 'Emergence and strange attractors', Philosophy of Science, Vol. 63, No. 2, pp.245-261.

Newman, M.E.J. (2005) 'Power laws, Pareto distributions and Zipf's law', Contemporary Physics, Vol. 46, No. 5, pp.323-351.

Nicolis, G. and Prigogine, I. (1989) Exploring Complexity, Freeman, San Francisco, CA.

Niklas, K.J. (1994) Plant Allometry: The Scaling of Form and Process, University of Chicago Press, Chicago, IL.

Orlikowski, W. (1996) 'Improvising organizational transformation over time: a situated change perspective', Information Systems Research, Vol. 7, No. 1, pp.63-92.

Park, J., Morel, B. and Madhavan, R. (2011) 'Big surf: self-organized criticality in M\&A waves', Working paper, Katz Graduate School of Business, University of Pittsburgh, Pittsburgh, PA. 
Paul, D.L., Butler, J.C., Pearlson, K.E. and Whinston, A.B. (1996) 'Computationally modeling organizational learning and adaptability as resource allocation: an artificial adaptive systems approach', Computational and Mathematical Organization Theory, Vol. 2, No. 4, pp.301-324.

Pepper, S.C. (1926) 'Emergence', Journal of Philosophy, Vol. 23, No. 9, pp.241-245.

Phillips, M.L., Clark, W.R., Nusser, S.M., Sovada, M.A. and Greenwood, R.J. (2004) 'Analysis of predator movement in prairie landscapes with contrasting grassland composition', Journal of Mammalogy, Vol. 85, No. 2, pp.187-195.

Pimm, S.L. (1982) Food Webs, University of Chicago Press, Chicago, IL, (2nd ed., 2002).

Pines, D. (Ed.) (1988) 'Emerging syntheses in science', Proceedings of the Santa Fe Institute, Vol. 1, Addison-Wesley, Reading, MA.

Podobnik, B., Fu, D., Jagric, T., Grosse, I. and Stanley, H.E. (2006) 'Fractionally integrated process for transition economics', Physica A, Vol. 362, No. 2, pp.465-470.

Powell, W.W., White, D.R., Koput, K.W. and Owen-Smith, J. (2005) 'Network dynamics and field evolution', American Journal of Sociology, Vol. 110, No. 4, pp.1132-1205.

Preston, F.W. (1948) 'The commonness, and rarity, of species', Ecology, Vol. 29, No. 3, pp.254-283.

Prigogine, I. (1955) An Introduction to Thermodynamics of Irreversible Processes, Thomas, Springfield, IL.

Prigogine, I. and Stengers, I. (1984) Order Out of Chaos: Man's New Dialogue with Nature, Bantam, New York.

Rivkin, J.W. (2001) 'Reproducing knowledge: replication without imitation at moderate complexity', Organization Science, Vol. 12, No. 3, pp.274-293.

Russell, R.W., Hunt, G.L., Jr., Coyle, K.O. and Cooney, R.T. (1992) 'Foraging in a fractal environment: spatial patterns in a marine predator-prey system', Landscape Ecology, Vol. 7, No. 3, pp.195-209.

Salthe, S.N. (1985) Evolving Hierarchical System: Their Structure and Representation, Columbia University Press, New York.

Salthe, S.N. (1993) Development and Evolution: Complexity and Change in Biology, Bradford/MIT Press, Cambridge, MA.

Sanchez, R. and Mahoney, J.T. (1996) 'Modularity, flexibility, and knowledge management in product and organization design', Strategic Management Journal, Winter Special Issue, Vol. 17, pp.63-76.

Sanders, T.I. and McCabe, J.A. (2003) The Use of Complexity Science: A Survey of Federal Departments and Agencies, Private Foundations, Universities, and Independent Education and Research Centers, a Report of the US Department of Education, Washington Center for Complexity and Public Policy, Washington, DC.

Saviotti, P.P. and Mani, G.S. (1998) 'Technological evolution, self-organization, and knowledge', Journal of High Technology Management Research, Vol. 9, No. 2, pp.255-270.

Schieve, W. and Allen, P. (Eds.) (1982) Self-Organization and Dissipative Structures: Applications in the Physical and Social Sciences, University of Texas Press, Austin, TX.

Schilling, M.A. (2000) 'Toward a general modular systems theory and its application to interfirm product modularity', Academy of Management Review, Vol. 25, No. 2, pp.312-334.

Schmidt-Nielsen, K. (1984) Scaling: Why is Animal Size so Important? Cambridge University Press, Cambridge, UK.

Schrödinger, E. (1944) What is Life? Cambridge University Press, Cambridge, UK, (2nd ed. published in 1992).

Schumpeter, J. (1934) The Theory of Economic Development, Harvard University Press, Boston, MA.

Selznick, P. (1943) 'An approach to a theory of bureaucracy', American Sociological Review, Vol. 8, No. 1, pp.47-54. 
Shinchi, T., Kitazoe, T., Nishimura, H., Tabuse, M., Azuma, N. and Aoki, I. (2002) 'Fractal evaluations of fish school movements in simulations and real observations', Artificial Life Robotics, Vol. 6, Nos. 1-2, pp.36-43.

Shulman, J.M. (with Stalkamp, T.T.) (2004) 'Getting bigger by growing smaller', Financial Times, Prentice Hall, New York.

Siggelkow, N. and Levinthal, D.A. (2005) 'Escaping real (non-benign) competency traps: linking the dynamics of organizational structure to the dynamics of search', Strategic Organization, Vol. 3, No. 1, pp.85-115.

Siggelkow, N. and Rivkin, J.W. (2006) 'When exploration backfires: unintended consequences of multilevel organizational search', Academy of Management Journal, Vol. 49, No. 4, pp.779-795.

Simon, H.A. (1962) 'The architecture of complexity', Proceedings of the American Philosophical Society, Vol. 106, No. 6, pp.467-482.

Sims, D.W. et al. (2008) 'Scaling laws of marine predator search behaviour', Nature, Vol. 451, No. 7182, pp.1098-1103.

Slevin, D. and Covin, J. (1997) 'Time, growth, complexity, and transitions: entrepreneurial challenges for the future', Entrepreneurship Theory and Practice, Winter, Vol. 22, No. 2, pp.53-68.

Smith, C. and Gemmill, G. (1991) 'Change in the small group: A dissipative structure perspective', Human Relations, Vol. 44, No. 7, pp.697-716.

Solé, R.V., Alonso, D., Bascompte, J. and Manrubia, S.C. (2001) 'On the fractal nature of ecological and macroevolutionary dynamics', Fractals, Vol. 9, No. 1, pp.1-16.

Sornette, D. (2006) Critical Phenomena in Natural Sciences: Chaos, Fractals, Selforganization and Disorder: Concepts and Tools, 2nd ed., Springer-Verlag, Heidelberg, Germany.

Sornette, D. and Woodard, R. (2009) 'Financial bubbles, real estate bubbles, derivative bubbles, and the financial and economic crisis', Quantitative Finance, available at http://arXiv.org/abs/0905.0220 (accessed on 15 March 2010).

Sornette, D. and Zhou, W-X. (2006) 'Predictability of large future changes in major financial indices', International Journal of Forecasting, Vol. 22, No. 1, pp.153-168.

Sornette, D., Deschâtres, F., Gilbert, T. and Ageon, Y. (2004) 'Endogenous versus exogenous shocks in complex networks', Physics Review Letters, Vol. 93, No. 22, pp.228701-1-4.

Stacey, R.D. (1992) Managing the Unknowable: Strategic Boundaries Between Order and Chaos in Organizations, Jossey-Bass, San Francisco, CA.

Stanley, M.H.R., Amaral, L.A.N., Buldyrev, S.V., Havlin, S., Leschhorn, H., Maass, P., Salinger, M.A. and Stanley, H.E. (1996) 'Scaling behaviour in the growth of companies', Nature (letters), Vol. 379, No. 6568, pp.804-806.

Stauffer, D. (1985) Introduction to Percolation Theory, Taylor and Francis, London.

Staw, B.M., Sandelands, L.E. and Dutton, J.E. (1981) 'Threat-rigidity effects in organizational behavior: a multi-level analysis', Administrative Science Quarterly, Vol. 26, No. 4, pp.501-524.

Stephan, G.E. (1983) 'A research note on deriving the square-cube law of formal organizations from the theory of time-minimization', Social Forces, Vol. 61, No. 3, pp.847-854.

Stephen, A. (1992) 'Emergence - a systematic view on its historical facets', in Beckermann, A., Flohr, H. and Kim, J. (Eds.): Emergence or Reduction? Essays on the Prospects of Nonreductive Physicalism, pp.25-48, Walter de Gruyter, Berlin.

Swenson, R. (1989) 'Emergent attractor and the law of maximum entropy production: foundations to a theory of general evolution', Systems Research, Vol. 6, No. 3, pp.187-197.

Swenson, R. (1992) 'Autocatakinetics, yes - autopoiesis, no: steps toward a unified theory of evolutionary ordering', International Journal of General Systems, Vol. 21, No. 2, pp.207-228.

Swenson, R. (1997) 'Thermodynamics and evolution', in Greenberg, G. and Haraway, M. (Eds.): Encyclopedia of Comparative Psychology, pp.217-218, Garland Publishers, New York. 
Taylor, L.R. (1984) 'Assessing and interpreting the spatial distributions of insect populations', Annual Review of Entomology, Vol. 29, No. 1, pp.321-357.

Thomas, C., Kaminska, R. and McKelvey, B. (2012) 'Building ambidexterity into a firm: the control/autonomy dilemma revisited', in Dibiaggio, L. and Meschi, P-X. (Eds.): Management in the Knowledge Economy: New Managerial Models for Success, pp.139-173, Pearson, Paris, France.

Thomas, C., Kaminska-Labbé, R. and McKelvey, B. (2005) 'Managing the MNC and exploitation/exploration dilemma: from static balance to irregular oscillation', Szulanski, G., Doz, Y. and Porac, J. (Eds.): Advances in Strategic Management: Expanding Perspectives on the Strategy Process, Vol. 22, pp.213-247, Elsevier, The Netherlands.

Tichy, N.M. and Sherman, S. (1994) Control Your Destiny or Someone Else Will, HarperCollins, New York.

Tremblay, Y., Roberts, A.J. and Costa, D.P. (2007) 'Fractal landscape method: an alternative approach to measuring area-restricted searching behavior', Journal of Experimental Biology, Vol. 210, No. 6, pp.935-945.

Tsuda, A. (1995) 'Fractal distribution of an oceanic Copepod Neocalanus cristatus in the Subarctic Pacific', Journal of Oceanography, Vol. 51, No. 3, pp.261-266.

Tushman, M.L. and Anderson, P. (1986) 'Technological discontinuities and organizational environments', Administrative Science Quarterly, Vol. 31, No. 3, pp.439-465.

Ulrich, H. and Probst, J.B. (Eds.) (1984) Self-Organization and Management of Social Systems, Springer-Verlag, Berlin.

von Bertalanffy, L. (1956) 'General system theory', General Systems Yearbook, Vol. 1, pp.1-10.

von Bertalanffy, L. (1968) General System Theory: Foundations, Development, Applications, Braziller, New York.

Weick, K.E. (1977) 'Organization design: organizations as self-designing systems', Organizational Dynamics, Vol. 6, No. 2, pp.30-46.

Weick, K.E. and Roberts, K. (1993) 'Collective mind in organizations: heedful interrelating on flight decks', Administrative Science Quarterly, Vol. 38, No. 3, pp.357-381.

West, B.J. (2006) Where Medicine Went Wrong, World Scientific, Singapore.

West, G.B. and Brown, J.H. (2004) 'Life's universal scaling laws', Physics Today, Vol. 57, No. 9, pp.36-42.

West, G.B., Brown, J.H. and Enquist, B.J. (1997) 'A general model for the origin of allometric scaling laws in biology', Science, Vol. 276, No. 5309, pp.122-126.

Whetten, D.A. (1989) 'What constitutes a theoretical contribution?' Academy of Management Review, Vol. 14, No. 4, pp.490-495.

Wicken, J. (1986) 'Evolutionary self-organization and entropic dissipation in biological and socioeconomic systems', Journal of Social and Biological Structures, Vol. 9, No. 3, pp.261-273.

Winter, S. (1984) 'Schumpeterian competition in alternative technological regimes', Journal of Economic Behavior and Organization, Vol. 5, Nos. 3-4, pp.287-320.

Woodward, J. (1958) Management and Technology, H.M.S.O., London.

Xiao, Y., Cheng, D. and Tang, S. (2002) 'Dynamic complexities in predator-prey ecosystem models with age-structure for predator', Chaos, Solitons and Fractals, Vol. 14, No. 9, pp.1403-1411.

Yalamova, R. and McKelvey, B. (2011) 'Using power laws and the Hurst coefficient to identify stock market trading bubbles', in Sundström, G. and Hollnagel, E. (Eds.): Governance and Control of Financial Systems: A Resilience Engineering Perspective, pp.85-105, Ashgate, Farnham, UK.

Yan, W., Woodard, R. and Sornette, D. (2010) 'Diagnosis and prediction of tipping points in financial markets: crashes and rebounds', Physics Procedia, Vol. 3, No. 5, pp.1-17.

Yule, G.U. (1925) 'A mathematical theory of evolution based on the conclusions of Dr. J.C. Willis', Philosophical Transactions of the Royal Society of London B, Vol. 213, pp.21-87. 
Zhou, W-X. and Sornette, D. (2002) 'Generalized q-analysis of log-periodicity: application to critical ruptures', Physical Review E, Vol. 66, No. 4, pp.129-136.

Zhou, W-X. and Sornette, D. (2003) 'Non-parametric analysis of log-periodic precursors to financial crashes', International Journal of Modern Physics C, Vol. 14, No. 8, pp.1107-1126.

Zimmerman, B. and Hurst, D. (1993) 'Breaking the boundaries: the fractal organization', Journal of Management Inquiry, Vol. 2, No. 4, pp.334-355.

Zipf, G.K. (1949) Human Behavior and the Principle of Least Effort, Addison-Wesley, Cambridge, MA.

Zohar, A. and Borkman, T. (1997) 'Emergent order and self-organization: a case study of alcoholics anonymous', Nonprofit and Voluntary Sector Quarterly, Vol. 26, No. 4, pp.527-552.

\section{Notes}

1 Steven Hawking, January 2000, quoted in Sanders and McCabe, (2003, p.5).

2 These admittedly fuzzy sets make an important distinction - it is analytically useful to show how they are historically separate so as to better understand the importance of, then, integrating them, a process that is currently underway. Two exceptions are worth noting: one of Prigogine's colleagues, Allen $(1975,1988,1993)$, writes more in the US coevolution and computational modelling tradition, while Santa Fe scholars Kelso et al. (1992) make the best statement of the European school's perspective (McKelvey, 2004) - though we hasten to note that Kelso was a student of, and coauthor with, Haken.

3 'Agent' is a general term used to designate semi-autonomous entities (i.e., 'parts' of systems): such entities as atoms, molecules, biomolecules, organelles, organs, organisms, species, processes, people, groups, firms, industries, and so on. In organisations, agents may include structures, departments, sub-units, units, divisions, etc.

4 Our logic here is the same as Kolmogorov's (1941) 'breakage theory', which Montroll and Badger (1974) built from for their theory of wealth creation (their eight criteria for becoming wealthy) - which are multiplicative and result in a PL formation. This is to say that there is some probability that networks will interact so as to produce (with a 0.1 probability in this example) the next stage networks.

5 The idea for this theory came from Val Bykoski's email message of 2003 titled 'Was Zipf's law - Now: Life is about hierarchies'. It originally appeared on the necsi.org email list, but is no longer accessible.

6 The single firms at the lower right of the table are very large firms like Nokia and Motorola (though not as large as Microsoft). At the upper left we see over 7,700 of the smallest firms. The Iansiti/Levien data do not show firm size (assets or \# of employees, etc.), but we know that the single firms down at the lower right of Table 2 are very large firms like Nokia and Motorola and that the 7,700 companies at the upper left are the smallest. Even so we get a pretty good straight-line power law distribution.

7 See also the classic work on this by Carneiro (1987). He studies how added complexity traits allow villages to avoid fission because of the so-called 'square/cube power law'. In biological organisms, when the energy demands of an organism's efforts to adapt (measured as volume) surpass its energy absorption rate (measured as surface) it undergoes fission. This is a somewhat more real-world explanation of Simon's near decomposability than his watchmaker story. Carneiro shows that villages overcome this law by taking advantage of more complexity traits.

8 Exceptions are Zimmerman and Hurst (1993), Stanley et al. (1996), Axtell (2001), Andriani and McKelvey (2007, 2009), Boisot and McKelvey (2010, 2012), McKelvey and Andriani (2010) and McKelvey (forthcoming). 